\title{
Performance of a Showerhead and Shaped Hole Film Cooled Vane at High Freestream Turbulence and Transonic Conditions
}

by

\author{
Andrew Newman \\ Thesis submitted to the faculty of the \\ Virginia Polytechnic Institute and State University \\ in partial fulfillment of the requirements for the degree of \\ Master of Science \\ in \\ Mechanical Engineering \\ Dr. Wing Ng, Chair \\ Dr. Srinath Ekkad, Co-Chair \\ Dr. Thomas Diller
}

May $5^{\text {th }}, 2010$

Blacksburg, Virginia

Keywords: Gas Turbines, High Freestream Turbulence, Film Cooling, Shaped Hole, Heat

Transfer, Transonic Cascade

Copyright @2010 Andrew Newman 


\title{
Performance of a Showerhead and Shaped Hole Film Cooled Vane at High Freestream Turbulence and Transonic Conditions
}

\author{
Andrew Newman
}

\begin{abstract}
An experimental study was performed to measure surface Nusselt number and film cooling effectiveness on a film cooled first stage nozzle guide vane using a transient thin film gauge (TFG) technique. The information presented attempts to further characterize the performance of shaped hole film cooling by taking measurements on a row of shaped holes downstream of leading edge showerhead injection on both the pressure and suction surfaces (hereafter PS and $\mathrm{SS}$ ) of a $1^{\text {st }}$ stage NGV. Tests were performed at engine representative Mach and Reynolds numbers and high inlet turbulence intensity and large length scale at the Virginia Tech Transonic Cascade facility. Three exit Mach/Reynolds number conditions were tested: 1.0/1,400,000; 0.85/1,150,000; and 0.60/850,000 where Reynolds number is based on exit conditions and vane chord. At Mach/Reynolds numbers of 1.0/1,450,000 and 0.85/1,150,000 three blowing ratio conditions were tested: $\mathrm{BR}=1.0,1.5$, and 2.0. At a Mach/Reynolds number of 0.60/850,000, two blowing ratio conditions were tested: $\mathrm{BR}=1.5$ and 2.0. All tests were performed at inlet turbulence intensity of $12 \%$ and length scale normalized by leading edge diameter of 0.28 . Film cooling effectiveness and heat transfer results compared well with previously published data, showing a marked effectiveness improvement (up to $2.5 \mathrm{x}$ ) over the showerhead only NGV and agreement with published showerhead-shaped hole data. Net heat flux reduction was shown to increase substantially (average 2.6x) with the addition of shaped holes, with an increase (average $1.6 \mathrm{x})$ in required coolant mass flow. Heat transfer and effectiveness augmentation with increasing blowing ratio was shown on the pressure side, however the suction side was shown to be less sensitive to changing blowing ratio. Boundary layer transition location was shown to be within a consistent region on the suction side regardless of blowing ratio and exit Mach number.
\end{abstract}




\section{Acknowledgements}

I would like to first thank my committee, Dr. Wing Ng, Dr. Srinath Ekkad, and Dr. Tom Diller for their help and guidance through this work. I have learned so much about myself and engineering from the guidance of Dr. Ekkad and Dr. Ng that it is impossible to put to words.

I would also like to thank Dr. Luzeng Zhang and Dr. Hee Koo Moon at Solar Turbines, Inc. for providing the opportunity for this research. It was a long road to get to this point, and their patience and support has been greatly appreciated. Along with this, thanks to Dr. Richard Anthony at AFRL for providing us with TFGs.

Thanks also goes out to those in my research group who have helped by way of discussion and analysis, without them this research project would have been impossible. So, a special thanks to Colin Reagle, Song Xue, Santosh Abraham, and Kapil Panchal.

Also, I am greatly indebted to the mechanical engineering machine shop for their help in building the tunnel hardware that made this all possible (and for bluegrass pickin' diversions at lunchtime). Thanks to Bill Songer, James Dowdy, Johnny Cox, and Tim Kessinger.

Finally, I would like to thank my wife Beth, and my parents for putting up with me throughout this experience. Their love and support kept me going through all the tough times and long nights. 


\section{Table of Contents}

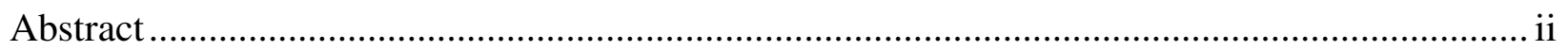

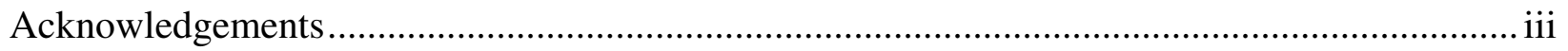

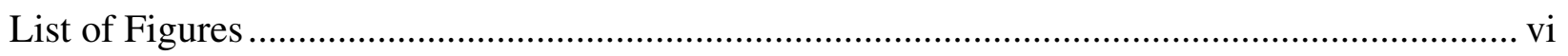

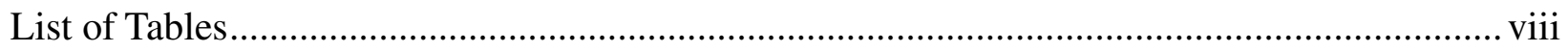

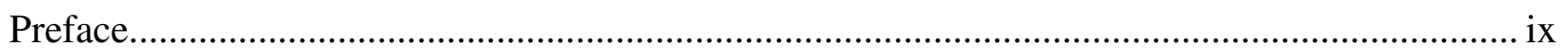

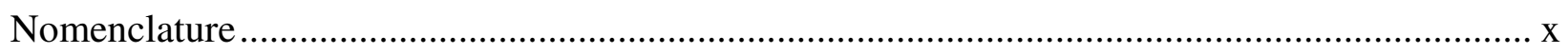

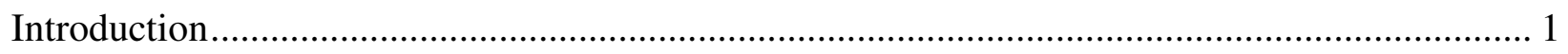

Experimental Facility and Instrumentation.................................................................... 3

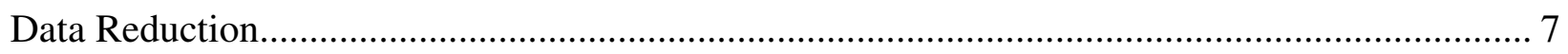

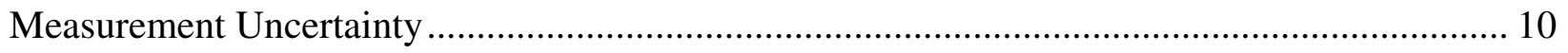

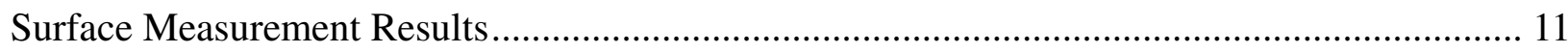

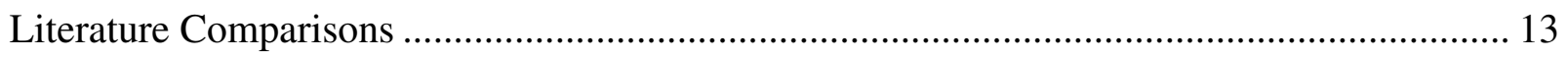

Laminar and Turbulent Flat Plate Correlation.................................................................... 15

Comparison with Showerhead-Only Vane .......................................................................... 17

Effect of Exit Mach Number on Film Effectiveness ............................................................... 19

Effect of Blowing Ratio on Film Effectiveness...................................................................... 21

Effect of Exit Mach Number on Nusselt Number .............................................................. 23

Effect of Blowing Ratio on Nusselt Number................................................................... 25

NHFR Comparison ........................................................................................................ 27

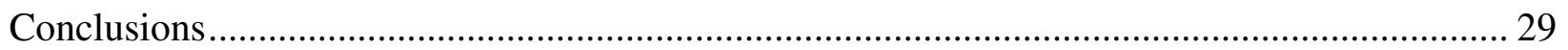

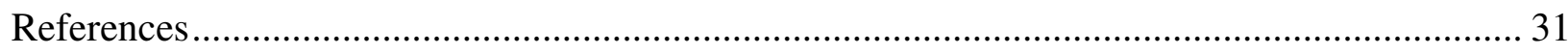

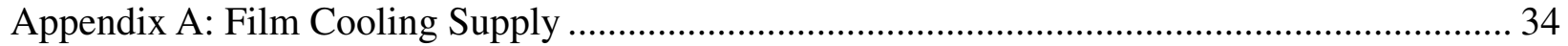

Appendix B: Thin Film Gauge Instrumentation ........................................................................ 37

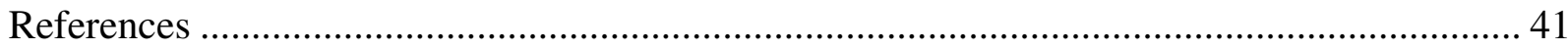

Appendix C: Measurement Uncertainty ………………………………………….............. 42

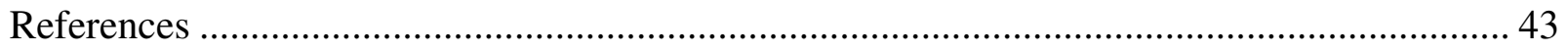

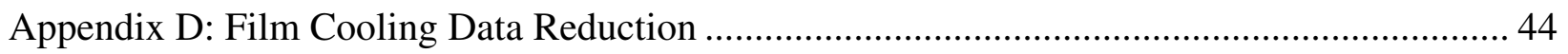

Chilled Coolant and Dual Regression Overview.................................................................... 44

Recovery Temperature .............................................................................................. 45

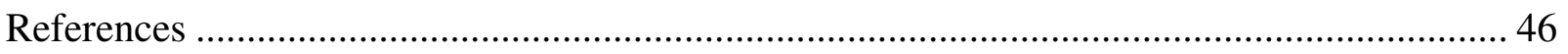


Appendix E: Tabulated Heat Transfer, Adiabatic Effectiveness, and NHFR Comparison Data .. 47 


\section{List of Figures}

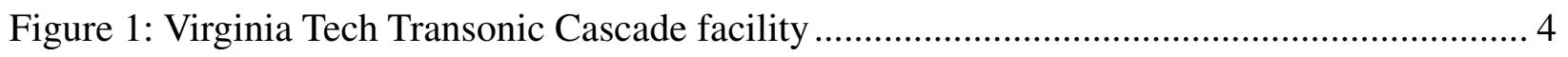

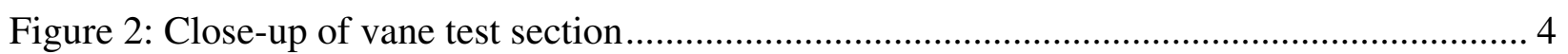

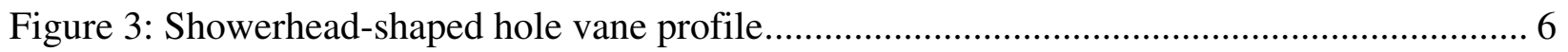

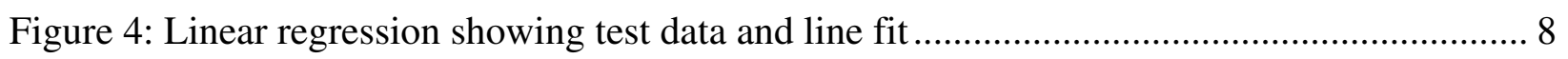

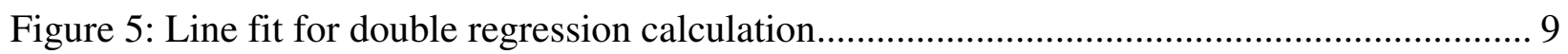

Figure 6: PS effectiveness literature comparison.............................................................. 13

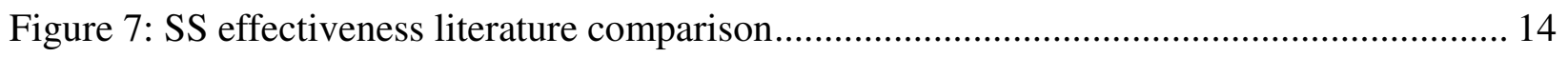

Figure 8: PS Mex $=0.85 \mathrm{BR}=2.0$ data compared with flat plate correlations ............................ 16

Figure 9: SS Mex = 0.85 BR = 2.0 data compared with flat plate correlations ............................ 17

Figure 10: Film cooling effectiveness comparison at $\mathrm{Mex}=0.85, \mathrm{BR}=2.0 \ldots \ldots \ldots \ldots \ldots \ldots \ldots \ldots \ldots \ldots . . . . . . . . . . .17$

Figure 11: Film cooling Nusselt number comparison, $\mathrm{Mex}=0.85, \mathrm{BR}=2.0 \ldots \ldots \ldots \ldots \ldots \ldots \ldots \ldots \ldots \ldots . . .19$

Figure 12: Effect of exit Mach number on film effectiveness distribution, $B R=1.0$................. 20

Figure 13: Effect of exit Mach number on film effectiveness distribution, $B R=1.5$................. 20

Figure 14: Effect of exit Mach number on film effectiveness distribution, $B R=2.0$................. 21

Figure 15: Effect of blowing ratio on film effectiveness, Mex $=0.60 \ldots \ldots \ldots \ldots \ldots \ldots \ldots \ldots \ldots \ldots \ldots \ldots \ldots . . . .22$

Figure 16: Effect of blowing ratio on film effectiveness, Mex $=0.85 \ldots \ldots \ldots \ldots \ldots \ldots \ldots \ldots \ldots \ldots \ldots \ldots \ldots . . . . .22$

Figure 17: Effect of blowing ratio on film effectiveness, Mex $=1.0 \ldots \ldots \ldots \ldots \ldots \ldots \ldots \ldots \ldots \ldots \ldots \ldots \ldots . . .23$

Figure 18: Effect of exit Mach number on Nusselt number distribution, $B R=1.0$..................... 24

Figure 19: Effect of exit Mach number on Nusselt number distribution, $B R=1.5$..................... 24

Figure 20: Effect of exit Mach number on Nusselt number distribution, $B R=2.0$................... 25

Figure 21: Effect of blowing ratio on Nusselt Number distribution, Mex $=0.60$ …………........ 26

Figure 22: Effect of blowing ratio on Nusselt number distribution, Mex $=0.85$......................... 26

Figure 23: Effect of blowing ratio on Nusselt number distribution, Mex $=1.0 \ldots \ldots \ldots \ldots \ldots \ldots \ldots \ldots \ldots . . .27$

Figure 24: Comparison of NHFR from Nasir et al. [27] with the present study .......................... 28

Figure A 1: Coolant supply circuit measurement section ................................................................ 34

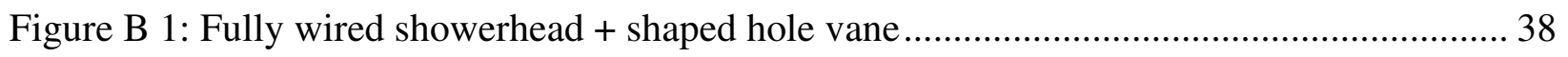

Figure B 2: Close up of SS TFGs showing soldered lead wires and epoxy covering ................... 39

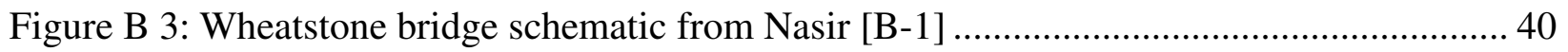

Figure D 1: Tunnel temperature response vs. time ………….................................................... 44 
Figure D 2: Vane heat flux response vs. Time .... 


\section{List of Tables}

Table 1: Showerhead-shaped hole vane parameters ........................................................... 5

Table 2: Film cooling design parameters ................................................................................. 5

Table 3: Relationship of mass flux and blowing ratio to density ratio .................................... 10

Table 4: Test matrix of surface measurements ........................................................................ 11

Table 5: Relationship between showerhead and shaped hole BR ......................................... 12

Table C 1: Uncertainties for single and double run regression technique .............................. 43

Table E 1: Heat Transfer and Film Effectiveness Data, Mex $=0.60$...................................... 47

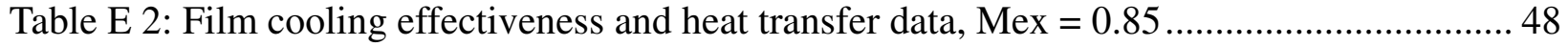

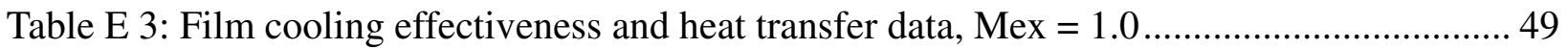

Table E 4: Normalized heat transfer coefficient and NHFR, Mex $=0.85, \mathrm{BR}=2.0 \ldots \ldots \ldots \ldots \ldots \ldots . . .50$ 


\section{Preface}

This thesis is intended to be submitted to the ASME IGTI Turbo Expo 2011 in Vancouver, British Columbia. Certain specifics about testing, instrumentation, and data reduction

have been left out of the body of the thesis as a result. Please refer to the appendices for more specific information on these topics. 


\section{Nomenclature}

$k$

$\mathrm{M}$

M

Re

$\mathrm{Nu}$

PS

q"

$r$

SS

T

$\mathrm{t}$

TFG

Tu

U

X

C

y

D

A

BR

LE

NHFR

$\dot{m}$

\section{Greek}

$\gamma$

$\rho$

$\eta$

$\varphi$

\section{Subscripts}

$\infty$

freestream 


$\begin{array}{ll}a w, w & \text { adiabatic wall, wall } \\ e x & \text { exit } \\ \text { i } & \text { initial, inlet } \\ o & \text { uncooled } \\ r & \text { recovery } \\ s & \text { surface } \\ L & \text { surface distance }\end{array}$




\section{Introduction}

As gas turbine manufacturers ever strive for higher efficiency and increased output from their products, turbine inlet temperatures have been increasing as a way to meet this end. The industry is already to a point where turbine inlet temperatures have reached greater values than blade and vane materials can withstand. In response to this problem, techniques such as complex internal and film cooling schemes and thermal barrier coatings have been employed to help increase engine component life and performance. This study attempts to further characterize the performance of shaped hole film cooling by taking measurements on a row of shaped holes downstream of leading edge showerhead injection on both the pressure and suction surfaces (hereafter PS and SS) of a $1^{\text {st }}$ stage NGV. Data is not readily available in the literature for the performance of a single row of shaped holes with showerhead interaction at high freestream turbulence intensity (12\%), large length scale, and engine-realistic Mach and Reynolds numbers.

Initial research performed by Goldstein et al. [1] demonstrated the potential of shaped hole film cooling above and beyond that of cylindrical holes in simplified-geometry flat plate experiments. Since that time, many others have explored the effects of injection angle, row spacing, row interaction, hole shaping, and many other parameters that have a bearing on film cooling performance. Many have looked into the effect of hole shaping by way of low speed flat plate studies such as Schmidt et al. [2], Gritsch et al. [3], and Yu et al. [4]. Studies such as these explore different expansion angles is the span and streamwise directions, often comparing back to rows of cylindrical holes to emphasize shaped hole performance benefits. Studies such as Bell et al. [5], Dittmar et al. [6], and Yuen et al. [7] have expanded on Goldstein et al. [1] to include comparisons of single and multiple rows of fan shaped holes to multiple rows of cylindrical holes with compound injection and rows of slot-type holes. As it has proved so beneficial to cylindrical holes, compound injection for shaped holes has also been a topic of interest in the previous three studies as well. Many other design factors have been explored by way of low speed flat or curved plate experiments such as: hole trenching and tabs (Lu et al. [8], Dhungel et al. [9]), shaped hole channel and surface flowfields (Wittig et al. [10], Thole et al. [11], Saumweber and Schulz [12]), effect of mainstream turbulence (Saumweber et al. [13]) and row spacing (Saumweber and Schulz [12]) to name a few. 
Shaped hole research has also been performed on NGVs in low-speed linear cascades. These studies tend to approximate engine Reynolds numbers by way of scaling, however they do not accurately represent engine-realistic surface Mach number. Colban et al. [14] performed heat transfer and film effectiveness measurements in a low-speed cascade using a steady state IR technique. This study looked at the effect of upstream blowing, and showed that the presence of upstream blowing reduced the incidence of jet-liftoff at higher blowing ratios. Colban et al. [15] also performed a comparison of experimental shaped hole data with CFD using different turbulence models, showing that the RNG $k-\varepsilon$ turbulence model better predicted effectiveness levels. Chappell et al. [16] performed a comparison of hole types and angles in a low speed cascade, concluding that compound angle had more effect on film cooling performance than hole shape.

In addition to low speed cascade studies, others have performed curved or flat plate studies at transonic Mach numbers to evaluate shaped hole performance. Wittig et al. [10] explored internal and external flowfield on a transonic flat plate rig. Furukawa et al. [17] explored the effects of hole shape and angle on a suction side airfoil model finding that fan shaped holes at compound angles show a significant effectiveness benefit over shaped holes and cylindrical holes without compound injection.

There are many studies exploring fan shaped holes at low surface Mach numbers and/or with simplified geometry, however there are comparatively fewer with engine representative Mach numbers. Fewer still are fan shaped hole cascade studies performed on vanes at high turbulence and engine representative Mach and Reynolds numbers. Zhang and Pudupatty [18] and Zhang et al. [19] look at PS and SS film effectiveness (respectively) on a first stage NGV with showerhead and shaped hole film cooling. Tests were performed at transonic exit Mach numbers $(0.74$ and $0.61)$ and high inlet turbulence intensity (12\%). Their findings in both cases were that upstream injection reduced the tendency of jet liftoff at high blowing ratios, and that little effectiveness benefit was seen from shaped holes at blowing ratios above 2. Zhang and Pudupatty [18] also found that at higher blowing ratios, showerhead injection augmented the effectiveness of downstream film cooling rows on the PS. Schneider et al. [20] performed a study to investigate the effects of showerhead and PS row interaction at high inlet turbulence and high Mach number. 
Their findings indicated that the increased turbulence created by showerhead injection caused more rapid film diffusion of downstream rows of shaped holes. Other studies such as Thurman et al. [21] have looked at heat transfer due to shaped hole film cooling, showing local increases in injection regions.

In addition to linear cascade studies others have explored rows of shaped holes in annular cascades. Guo et al. [22] looked at the effect of using foreign gasses for coolant to achieve engine-representative density ratios in a transonic annular cascade. Sargison et al. [23] compared a coverging-slot hole geometry to fan shape holes in the same facility as Guo et al. [22].

This paper will present the results of heat transfer and effectiveness measurements on a film cooled NGV with five rows of showerhead film cooling and one row of fan shaped holes on both the pressure and suction sides. These results are measured at three engine-representative Mach/Reynolds numbers and high inlet turbulence. The main objectives of this paper are to: investigate the effect of Mach number and blowing ratio on showerhead and downstream shaped hole film cooling, to compare showerhead only with combined showerhead and shaped hole film cooling at multiple blowing ratios and Mach numbers, and to perform a NHFR comparison to illustrate the overall effect of adding shape hole cooling rows.

\section{Experimental Facility and Instrumentation}

Tests were performed in the Virginia Tech Transonic Cascade tunnel. This is a transient blowdown facility, a schematic of which can be seen in Figure 1. The facility is capable of exit Mach numbers from 0.4 to 1.2 , with flow rates of 10 pounds-mass per second. The facility is also equipped with a heat exchanger capable of heating the mainstream flow to $150^{\circ} \mathrm{C}\left(423^{\circ} \mathrm{K}\right)$ for heat transfer testing. A control valve situated upstream of the test section allows for control of Mach number and tunnel response. For heat transfer testing there is a 10-15 second window of steady tunnel response in which data is taken. Inlet turbulence is generated directly upstream of the test section by way of a passive mesh grid. The turbulence grid and its relation to the cascade can be seen in Figure 2 For these experiments this grid generates a turbulence intensity of $12 \%$ and turbulence length scale nondimensionalized by leading edge diameter of 0.28 . This facility 
has been used by Reagle et al. [24], Bolchoz et al. [25], and Nasir et al. [26, 27] for vane and blade aerodynamic and heat transfer testing.

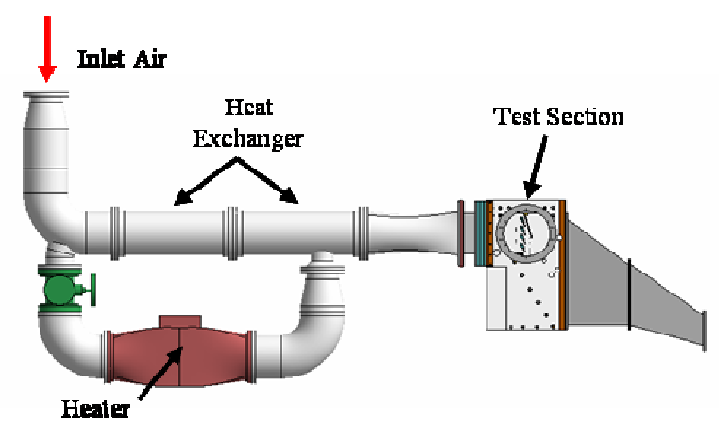

Figure 1: Virginia Tech Transonic Cascade facility

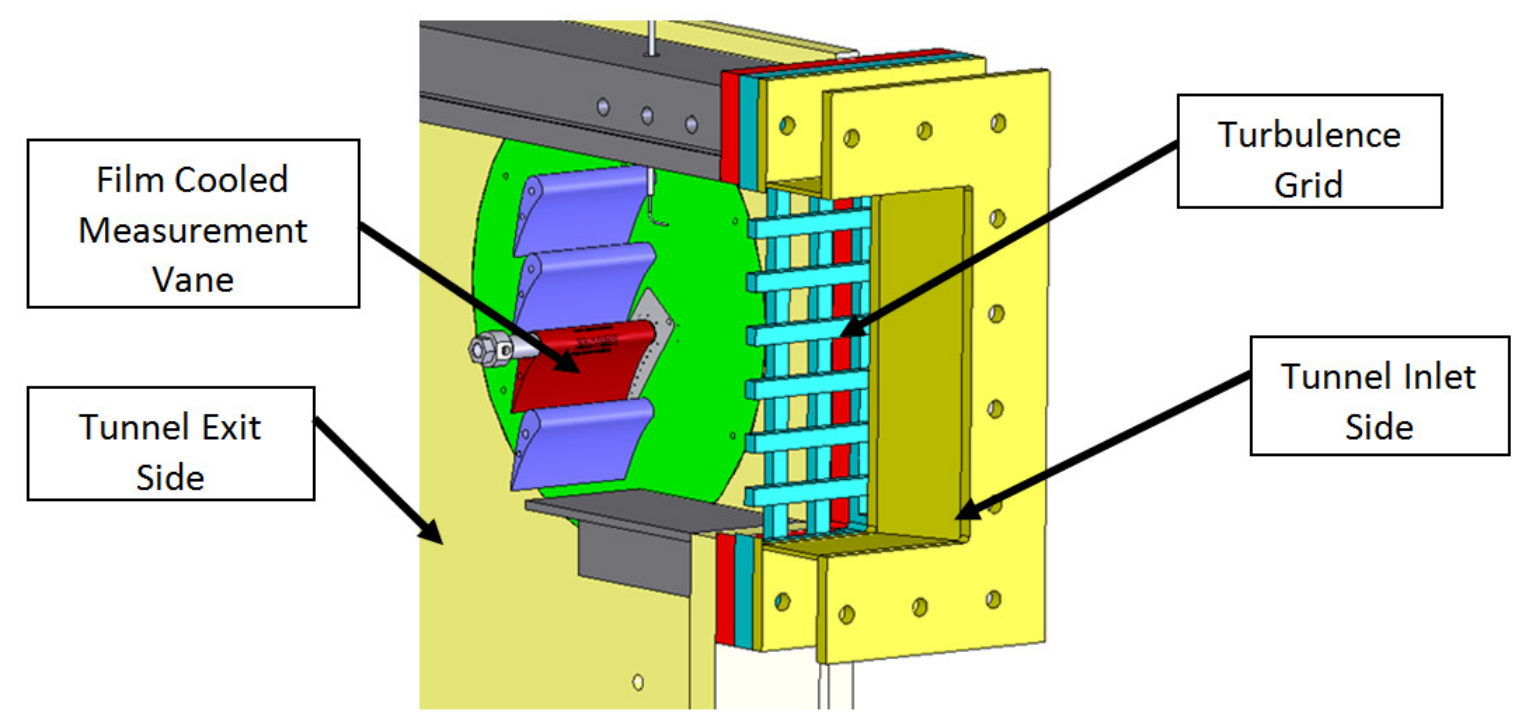

Figure 2: Close-up of vane test section

The vane cascade consists of four full vane models and two half-vanes. The vane profile is that of a first stage NGV provide by Solar Turbines, Inc., and is scaled 1.5x to match engine Reynolds numbers. Detailed aerodynamic performance of this vane cascade has been previously published by Nasir et al. [26]. Details on the vane geometry can be found below in Table 1 . 


\section{Table 1: Showerhead-shaped hole vane parameters}

\begin{tabular}{|c|c|c|}
\hline Chord & $C$ & 3.59 in. \\
\hline Pitch & $P$ & 3.27 in. \\
\hline Span & - & $6.00 \mathrm{in}$. \\
\hline Film-Cooled Span & - & 2.33 in. \\
\hline Inlet Angle & - & $0^{\circ}$ \\
\hline $\begin{array}{c}\text { Exit Angle } \\
\begin{array}{c}\text { Coolant Metering Hole } \\
\text { Diameter }\end{array}\end{array}$ & - & $73.5^{\circ}$ \\
\hline
\end{tabular}

Heat transfer measurements are taken on the center vane in the cascade. This vane is made of Corning Macor® machineable glass-ceramic. Macor ${ }^{\circledR}$ is chosen for its relatively low thermal diffusivity and conductivity, allowing for the use of a 1-D semi-infinite assumption in data reduction. The center vane has a total of seven rows of film cooling holes: Five rows of showerhead cooling on the LE, one row of shaped holes on the SS and one row of shaped holes on the PS. Table 2 lists details of the vane's film cooling design, and Figure 3 shows the vane profile and film cooling configuration. The shaped hole profiles are cut in the Macor® by a laser drilling method by the Connecticut Center for Advanced Technology.

Table 2: Film cooling design parameters

\begin{tabular}{|c|c|c|c|}
\hline Row & $\begin{array}{c}\text { Spanwise Injection } \\
\text { Angle, }^{\circ}\end{array}$ & $\begin{array}{c}\text { Streamwise Injection } \\
\text { Angle, }^{\circ}\end{array}$ & P/D \\
\hline Showerhead & $45^{\circ}$ & $90^{\circ}$ & 4.5 \\
\hline PS Shaped & $90^{\circ}$ & $35^{\circ}$ & 3.5 \\
\hline SS Shaped & $90^{\circ}$ & $50^{\circ}$ & 3.5 \\
\hline
\end{tabular}




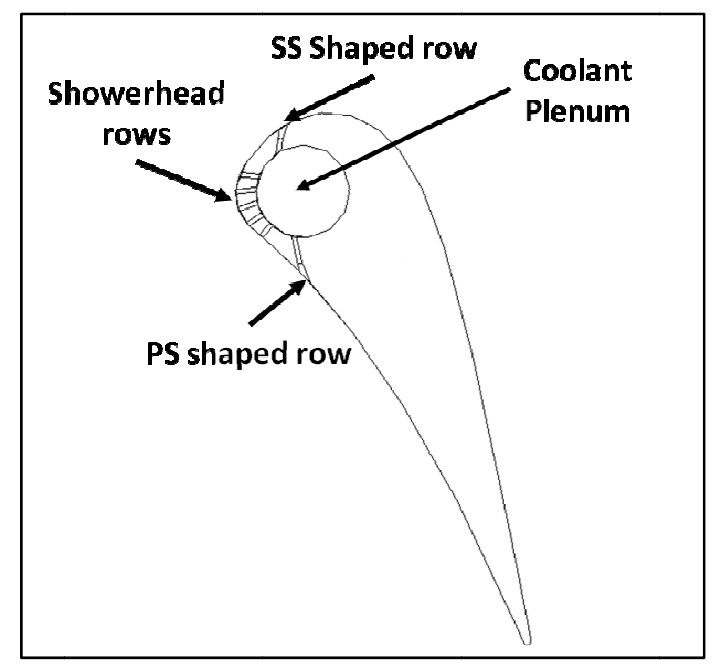

\section{Figure 3: Showerhead-shaped hole vane profile}

The film cooled vane is instrumented with 25 thin-film type heat flux sensors (TFGs). The gages used in this study are designed similar to that of Dooley and Oldfield [28] and are manufactured by AFRL using the method described in Joe [29]. The TFGs consist of a platinum sensing element and two gold leads sputtered onto a Kapton sheet, with the total gage thickness being about 50 microns (including the Kapton backing). The gages are applied to the measurement vane at $45 \%$ span, and are oriented such that the platinum sensing element is along a shaped hole centerline. Ten gages are instrumented on the PS of the vane, and 15 are instrumented on the SS.

As a result of the material properties of the platinum sensing element, the gages change resistance linearly with temperature. To convert resistance to a more easily measureable quantity, the gages are connected as one resistance arm in a Wheatstone bridge. The Wheatstone bridges are constructed as described in Joe [29]. Voltage is then measured across the Wheatstone bridge by a National Instruments data acquisition system at a sample rate of $1000 \mathrm{~Hz}$. Before assembling the wind tunnel, the gages are placed in a thermocouple incubator for calibration. The incubator temperature is increased to $80^{\circ} \mathrm{C}$ in five steps, and the vane temperature and gage resistance is measured at each step. The same process is repeated for decreasing temperature to check for gage hysteresis error. A line fit is then performed on this data, to determine the resistancetemperature calibration for each gage. 


\section{Data Reduction}

Three main variables are taken into consideration for data reduction: vane surface temperature, coolant temperature, and local recovery temperature. Vane surface temperature is measured by the TFGs, coolant temperature by a T-type thermocouple in the vane plenum, and local recovery temperature is calculated based on local Mach number measured by Nasir et al. [27] using surface pressure taps, inlet total temperature, and recovery factor. Recovery factor is defined as that of a turbulent flat-plate boundary layer, with $r=\operatorname{Pr}^{1 / 3}$. From these three variables, heat transfer coefficient $h$, and film effectiveness $\eta$ are desired.

To account for these two parameters a finite difference code described by Nasir et al. [27] and developed by Cress [30] is used to calculate heat flux, $q$ ”. This finite difference code solves the 1-D transient conduction equation for $q$ " (eq. 1) based on the time response of the vane surface temperature and the thermal properties of the vane material.

$$
\frac{\partial^{2} T}{\partial x^{2}}=\frac{1}{\alpha} \frac{\partial T}{\partial t}
$$

Due to experimental constraints, it is not practical to measure material back wall (vane inner) temperature, so a 1-D semi-infinite assumption is made and the back wall temperature is fixed at the vane initial temperature. The short duration of the tests ( 7 seconds) and low thermal diffusivity of Macor® ensure that heat has not sufficiently penetrated the vane surface so as to invalidate this assumption.

Heat transfer coefficient and film cooling effectiveness are derived using a linear regression method developed by Popp et al. [31]. This method starts with the convective heat transfer equation

$$
q^{\prime \prime}=h\left(T_{a w}-T_{w}\right)
$$

and the equation for film cooling effectiveness (non-dimensionalized adiabatic wall temperature).

$$
\eta=\frac{T_{a w}-T_{r}}{T_{c}-T_{r}}
$$


Equations 2 and 3 are then combined to yield an equation expressing heat transfer coefficient and film cooling effectiveness in the form $y=m x+b$.

$$
\frac{q^{\prime \prime}}{T_{r}-T_{c}}=h\left(\frac{T_{r}-T_{w}}{T_{r}-T_{c}}\right)-h \eta
$$

Quantities that are measured from the experiment are represented as $\mathrm{x}$ and $\mathrm{y}$ in this linear equation. These quantities can then be plotted, and a simple linear regression can be performed on the plot. The heat transfer coefficient can then be determined by the slope of the fitted line, and film cooling effectiveness can be determined by the $\mathrm{x}$-intercept of the fitted line. For this study heat transfer coefficient will be nondimensionalized by way of Nusselt number as defined in equation 5 .

$$
N u=\frac{h \cdot C}{k_{a}}
$$

Figure 4 shows the linear regression technique performed on a sample data set, with heat transfer coefficient and film effectiveness highlighted.

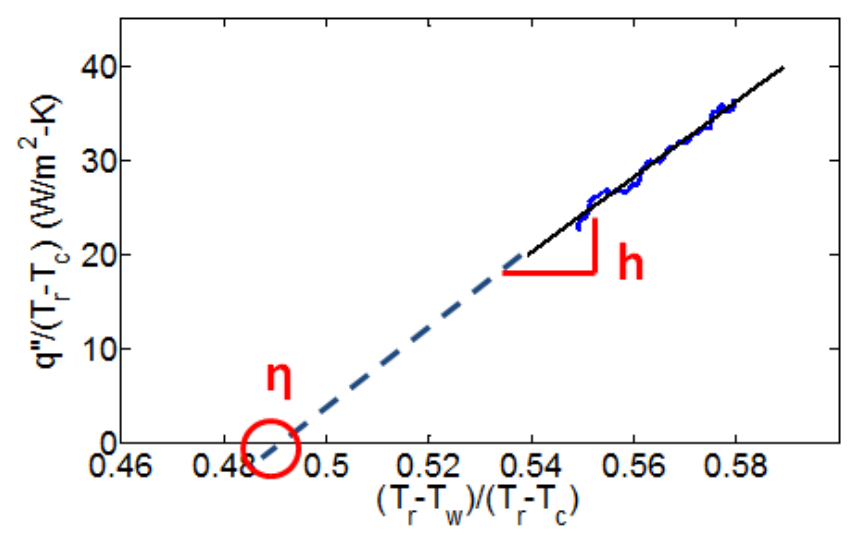

Figure 4: Linear regression showing test data and line fit 
To reduce experimental uncertainty a double-regression method was used, whereby two sets of data are used to perform the linear regression. For this technique two runs are performed at identical flow conditions but with different coolant temperatures. This technique reduces uncertainty by increasing the number of data points used for regression and adding points closer to the $\mathrm{x}$-axis, reducing the distance the line fit is extrapolated to calculate effectiveness. Figure 5 shows the line fit for a double regression run.

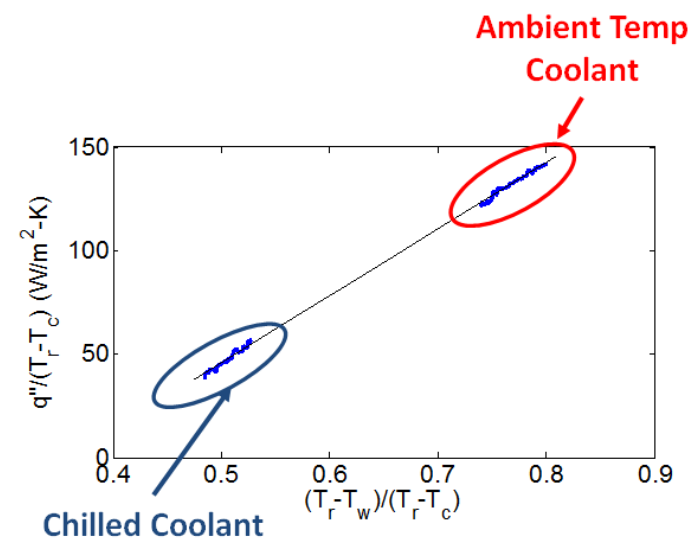

Figure 5: Line fit for double regression calculation

When using chilled coolant, the coolant to mainstream density ratio changes from the room temperature case. All room temperature runs were completed at a density ratio of 1.45 and all chilled coolant runs were completed at a density ratio of 1.85. To keep blowing ratio constant with the change in density ratio, tunnel settings were adjusted between the chilled and room temperature runs to match coolant plenum to mainstream pressure ratio. This results in a change in momentum flux ratio (MR) between chilled coolant runs and room temperature coolant runs. Momentum flux ratio is defined in equation 6, and momentum flux ratio for each DR and BR is shown in table 3.

$$
M R=\frac{B R^{2}}{D R}
$$




\section{Table 3: Relationship of mass flux and blowing ratio to density ratio}

\begin{tabular}{|c|c|c|}
\hline DR & BR & MR \\
\hline \multirow{3}{*}{1.45} & 1.0 & 0.69 \\
\cline { 2 - 3 } & 1.5 & 1.55 \\
\cline { 2 - 3 } & 2.0 & 2.75 \\
\hline \multirow{3}{*}{1.85} & 1.0 & 0.54 \\
\cline { 2 - 3 } & 1.5 & 1.22 \\
\cline { 2 - 3 } & 2.0 & 2.16 \\
\hline
\end{tabular}

Ekkad et al. [32] have shown that increasing coolant density ratio can have effects on film effectiveness and Nusselt number distributions. Specifically, they showed that at lower blowing ratios $(\mathrm{BR}<1)$ increasing coolant density augmented film effectiveness. For higher blowing ratios $(\mathrm{BR}>1)$ increasing coolant density showed no appreciable effect on film effectiveness distributions. The study also showed that increasing coolant density had the effect of lowering Nusselt number for all BRs tested. Based on this information, film effectiveness distributions from the present study should not be effected as all cases considered are at BR>1. The lack of matching MRs resulting from increasing coolant density will result in discrepancies in Nusselt number level, increasing experimental uncertainty. The experimental uncertainty as a result of changing MR is included in the overall uncertainty analysis performed below.

\section{Measurement Uncertainty}

Uncertainty is calculated based on errors present in measured data which are propagated first through the finite-difference calculation of $q$ " then through the linear regression of heat transfer coefficient and film effectiveness. To calculate overall uncertainty, errors present in the $\mathrm{x}$ and $\mathrm{y}-$ axis of the linear regression line-fit are quantified. Error in heat flux is calculated using Moffat's [33] perturbation method due to the finite difference code used to calculate this quantity. Brown and Coleman's [34] linear regression analysis is then used to calculate the uncertainty of heat transfer coefficient and film effectiveness based on the $\mathrm{x}$ and $\mathrm{y}$-axis uncertainties.

This analysis showed an average uncertainty in heat transfer coefficient of $\pm 4 \%$ and an average uncertainty in film effectiveness of \pm 0.05 . In addition to this analysis, tunnel repeatability was established for each Mach number case. 


\section{Surface Measurement Results}

Measurement results will first be compared with past studies performed by this group on a showerhead-only film cooled NGV using the same transient TFG technique. Results will also be compared to other available literature with similar Mach/Reynolds numbers, film cooling configurations, and turbulence levels. Following the comparison, comprehensive results at each of the test conditions listed in table 4 will be presented. Results will be presented in terms of Nusselt number distributions and film cooling effectiveness distributions.

Table 4: Test matrix of surface measurements

\begin{tabular}{|c|c|c|c|}
\hline \multicolumn{4}{|c|}{ Film Cooled Test Matrix } \\
\hline $\mathrm{Ma}$ & $\operatorname{Re}$ & $\mathrm{Tu}$ & BR, MFR \% \\
\hline \multirow{2}{*}{0.60} & \multirow{2}{*}{850,000} & \multirow{8}{*}{$12 \%$} & $1.5,1.04$ \\
\hline & & & $2.0,1.15$ \\
\hline \multirow{3}{*}{0.85} & \multirow{3}{*}{$1,150,000$} & & $1.0,0.85$ \\
\hline & & & $1.5,1.04$ \\
\hline & & & $2.0,1.15$ \\
\hline \multirow{3}{*}{1.00} & \multirow{3}{*}{$1,400,000$} & & $1.0,0.85$ \\
\hline & & & $1.5,1.04$ \\
\hline & & & $2.0,1.15$ \\
\hline
\end{tabular}

Three blowing/mass flow ratios were tested at two exit Mach numbers (Mex $=1.0$ and 0.85) with only two blowing/mass flow ratios tested at the low exit Mach number case of Mex $=0.60$. The low coolant flow rates required for $\mathrm{BR}=1.0$ at the low exit Mach number case of Mex $=$ 0.60 exceeded the lower physical limitations of the film cooling loop, resulting in nonrepeatability. Results will be reported in terms of exit Mach number and blowing ratio, where blowing ratio is defined as the ratio of coolant density and velocity to freestream density and velocity. Equation 7 shows this relationship.

$$
B R=\frac{\rho_{c} U_{c}}{\rho_{\infty} U_{\infty}}=\frac{\dot{m}_{c}}{A_{\text {holes }} \rho_{i} U_{i}}
$$

Mass flow ratio is the relationship of total coolant mass flow for all film cooling rows to passage mass flow as defined below in equation 8 .

$$
\operatorname{MFR} \%=\frac{\dot{m}_{c}}{\dot{m}_{p}}
$$


All seven rows of film cooling holes (five LE showerhead, one SS shaped, and one PS shaped) are fed from a common plenum. This results in varying local blowing ratios between rows of holes where PS blowing ratios are higher than those on the SS. This is a result of considerably higher surface velocities at the SS shaped holes. While the mass flow through the SS shaped holes is greater than that of the PS holes, the surface velocity difference between the PS and SS dominates the equation. On the PS, this results in higher blowing ratios due to a lower value of the surface velocity term in the denominator of equation 6. Table 5 shows the relationship between showerhead blowing ratio and shaped hole blowing ratio for each of the three blowing ratio cases tested. For ease of comparison, film cooling conditions will be indicated based on the equivalent blowing ratio for the showerhead region of the measurement vane or corresponding MFR.

Table 5: Relationship between showerhead and shaped hole BR

\begin{tabular}{|c|c|c|}
\hline BR Showerhead & BR PS Shaped & BR SS Shaped \\
\hline 2 & 3 & 1.36 \\
\hline 1.5 & 2.21 & 1.16 \\
\hline 1 & 1.68 & 1.05 \\
\hline
\end{tabular}

This thesis will compare data from the present study with data from Nasir et al. [27], a study performed in the same facility but with showerhead film cooling only. In order to compare film effectiveness and Nusselt number between the two film cooling designs, the increase in coolant mass flow required by the addition of two shaped hole rows to the existing showerhead film cooled vane must be quantified. To perform this analysis, total coolant mass flow rates for the showerhead and shaped hole vane from the present study at Mex $=0.85, \mathrm{BR}=2.0$ were averaged over multiple runs. This value was then divided by the total coolant mass flow rate for the showerhead only vane (Nasir et al. [27] at $\mathrm{Mex}=0.80, \mathrm{BR}=2.0$ ) averaged over multiple runs. The result of this simple calculation showed that the addition of shaped holes resulted in an average 1.6x increase in total coolant usage over the showerhead only film cooled vane presented in Nasir et al. [27]. 


\section{Literature Comparisons}

Figures 6 and 7 show comparisons of the present study with Zhang et al. [18, 19] and Schneider et al.[20]. Zhang et al. [18, 19] were performed on an NGV of the same profile with similar hole shapes, but different injection locations. Schneider et al. [20] is a showerheadshaped hole interaction study performed on the PS only. Both studies report only film cooling effectiveness and do not measure Nusselt number.

Results in this section will be plotted for the near hole region only, the entire blade surface will not be compared. Figure 6 is a pressure side results comparison where the left axis is the shaped hole injection location and streamwise distance on the PS increases to the right of the plot. Figure 7 is a comparison of SS effectiveness where the left axis is the shaped hole injection location, and streamwise distance down the SS increases to the right of the plot.

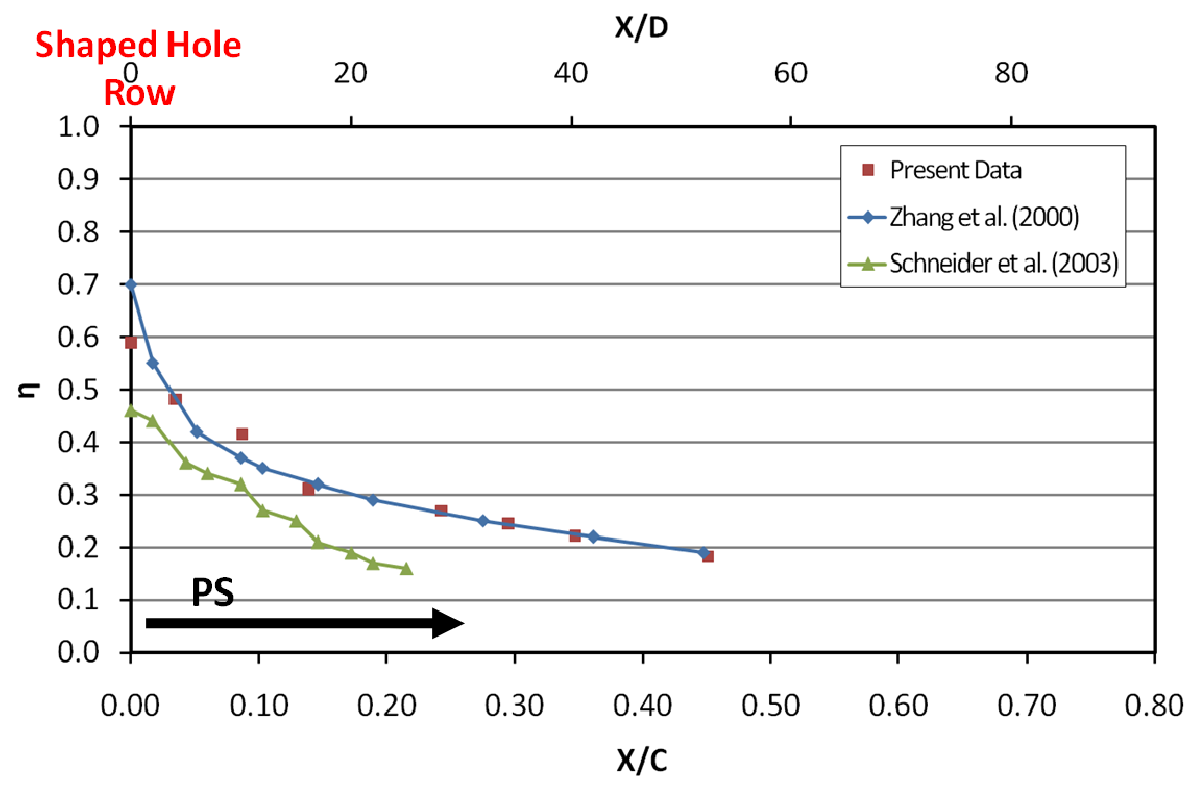

Figure 6: PS effectiveness literature comparison

The present study shows very good agreement with Zhang et al. [18] on the PS of the vane. Slight differences may be attributed to changes in injection location, but overall it shows a good match in trend and level. The comparison between Schneider et al. [20] is not as close as the comparison with Zhang et al. [18], however they still compare favorably. One of the main conclusions of Schneider et al. [20] was that upstream showerhead injection increased local 
turbulence resulting in faster shaped hole diffusion and lower effectiveness values. This may also be a function of row spacing. Both the present study and Zhang et al. [18] had significantly larger spacing between showerhead injection and the first row of shaped holes. This increased spacing may provide room for local turbulence due to showerhead injection to dissipate, resulting in less of a diffusion effect on the shaped hole rows and higher levels of effectiveness than reported by Schneider et al. [20].

On the SS, the present study again shows very good agreement with Zhang et al. [19]. Slight differences in trend and level may be explained by some of the differences in the studies. First, Zhang et al. [19] ran their tests at exit Mach numbers lower than the present study, possibly accounting for slightly lower effectiveness values in the region $10>\mathrm{X} / \mathrm{D}<40$. Second, Zhang et al. [19] had multiple rows of suction side injection at considerably different locations. The sharp decrease in effectiveness shown at $5<\mathrm{X} / \mathrm{D}<10$ may be a result of their first row of shaped holes being placed closer to the throat. This row of holes may be experiencing transition sooner than the present study, resulting in faster diffusion and effectiveness decay. The data plotted from Zhang et al. [19] in figure 7 is for the first row of shaped hole cooling on the suction side. In summary, the present data compares reasonably well with published data from similar studies.

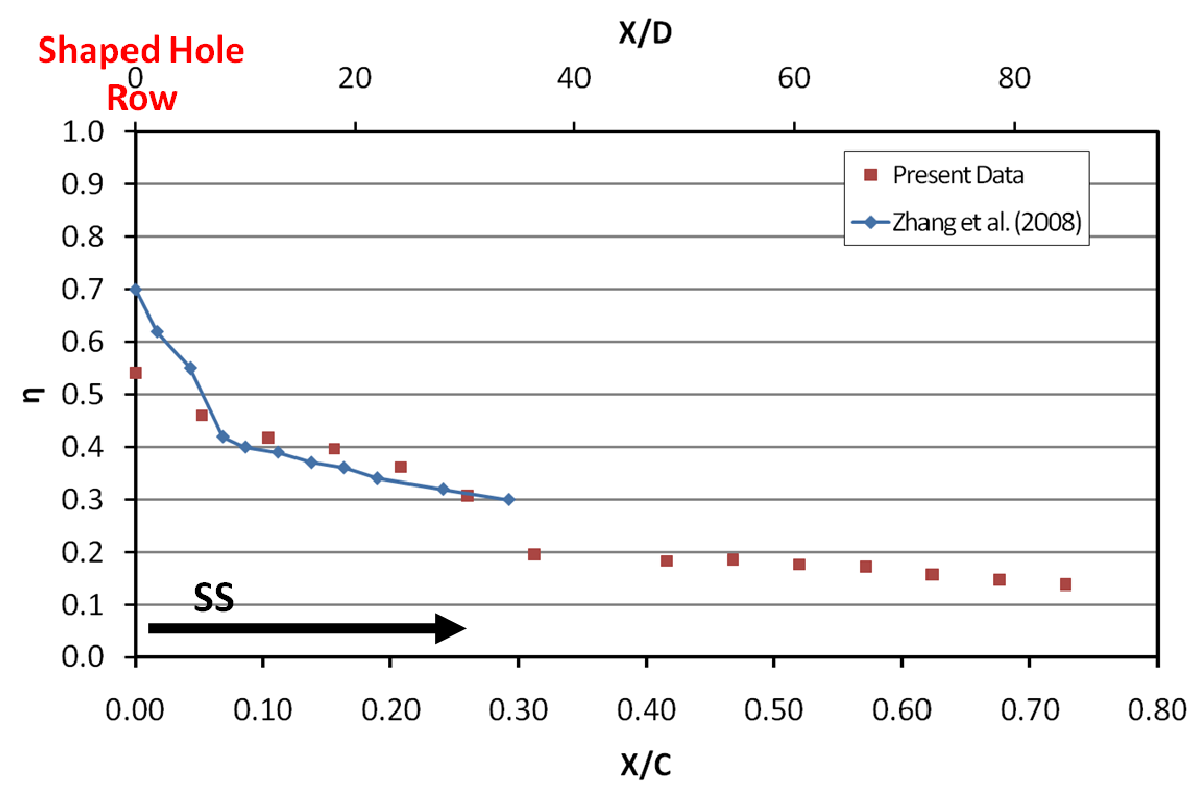

Figure 7: SS effectiveness literature comparison 


\section{Laminar and Turbulent Flat Plate Correlation}

Figures 8 and 9 show experimental Stanton number distributions from the present study compared with laminar and turbulent flat plate Stanton number predictions. This comparison is useful for gaining fundamental insight into how the boundary layer is behaving on the surface of the vane. It also serves to show whether or not the data falls within an acceptable range of values. For this comparison, the analytical solutions for laminar and turbulent flat plate Nusselt number as presented in Incorpera and Dewitt [35] are used. Equation 9 is the turbulent boundary layer equation and equation 10 is the laminar boundary layer equation.

$$
\begin{aligned}
& N u_{L}=0.332 \operatorname{Re}_{L}^{1 / 2} \operatorname{Pr}^{1 / 3} \\
& N u_{L}=0.0296 \operatorname{Re}_{L}^{4 / 5} \operatorname{Pr}^{1 / 3}
\end{aligned}
$$

Both of these equations use vane surface distance from the leading edge as the characteristic length parameter in the calculation of Nusselt number and Reynolds number. Results are then converted from Nusselt number to Stanton number using equations 11 and 12 below.

$$
\begin{gathered}
h=\frac{N u_{L} \cdot k_{a}}{x} \\
S t=\frac{h}{\rho_{L} U_{L} C_{p, \infty}}
\end{gathered}
$$

Figures 8 and 9 show experimental data at $\mathrm{Mex}=0.85$ and $\mathrm{BR}=2.0$ normalized in terms of Stanton number. Also plotted are the analytical Stanton number solutions for flat plate laminar and turbulent boundary layer cases calculated using equations 9 and 10 .

Figure 8 shows the comparison of PS data to the flat plate correlations. Experimental data shows a fairly good match with the turbulent boundary layer solution for most of the PS. The level of the data suggests that the boundary layer is turbulent for the entire length of the PS, and may be a result of high inlet turbulence intensity (12\%). This type of heat transfer augmentation resulting from high turbulence intensity has also been shown experimentally by Blair [36]. The presence of film cooling may also be effecting the experimental Stanton number distribution, 
creating the large heat transfer augmentation (1.8x the turbulent flat plate solution) seen at lower Reynolds numbers which correspond to the near shaped hole region.

Figure 9 shows the comparison on the SS, and boundary layer transition is clearly evident on the plot. Most of the data falls between the laminar and turbulent correlation lines up to the transition point, where data shifts to more closely follow the turbulent correlation. The effect of heat transfer augmentation due to film cooling and inlet turbulence can also be seen before transition in the level and slope difference between the correlations and experimental data.

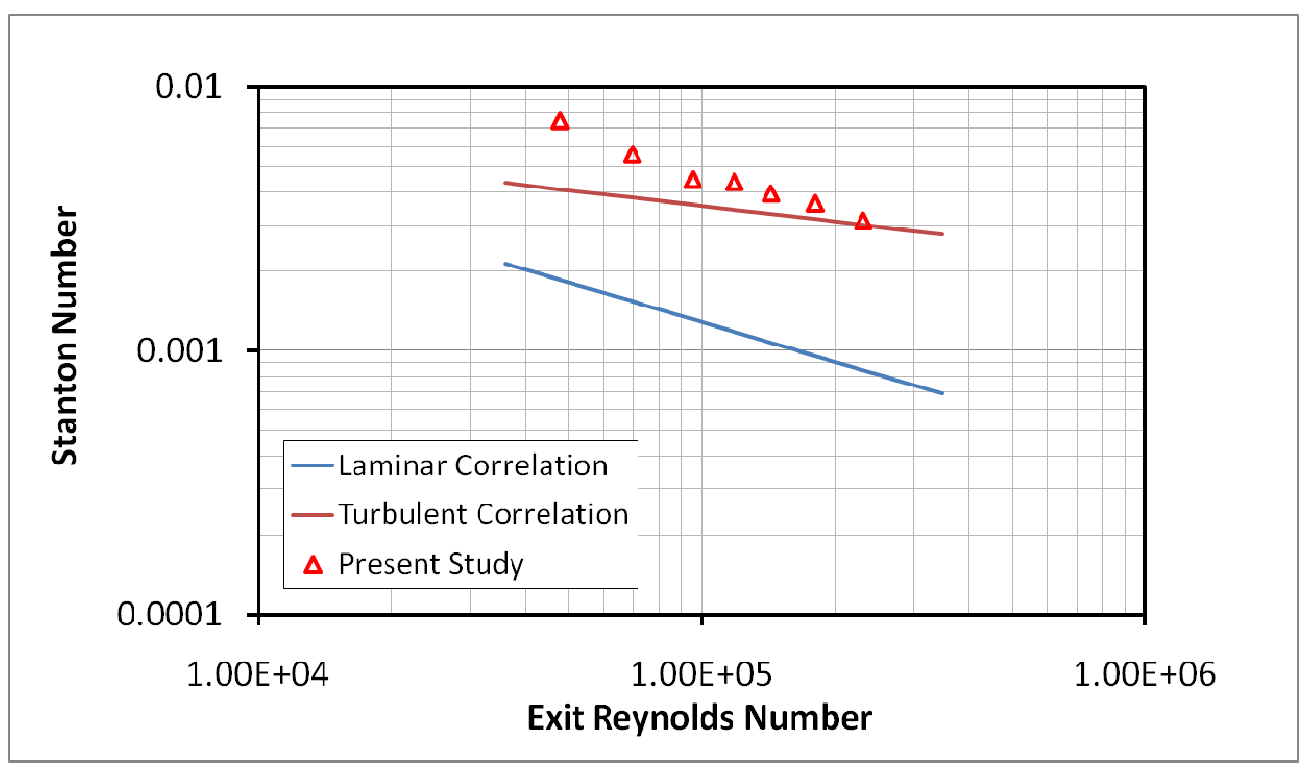

Figure 8: $\mathrm{PS} \mathrm{Mex}=0.85 \mathrm{BR}=2.0$ data compared with flat plate correlations 


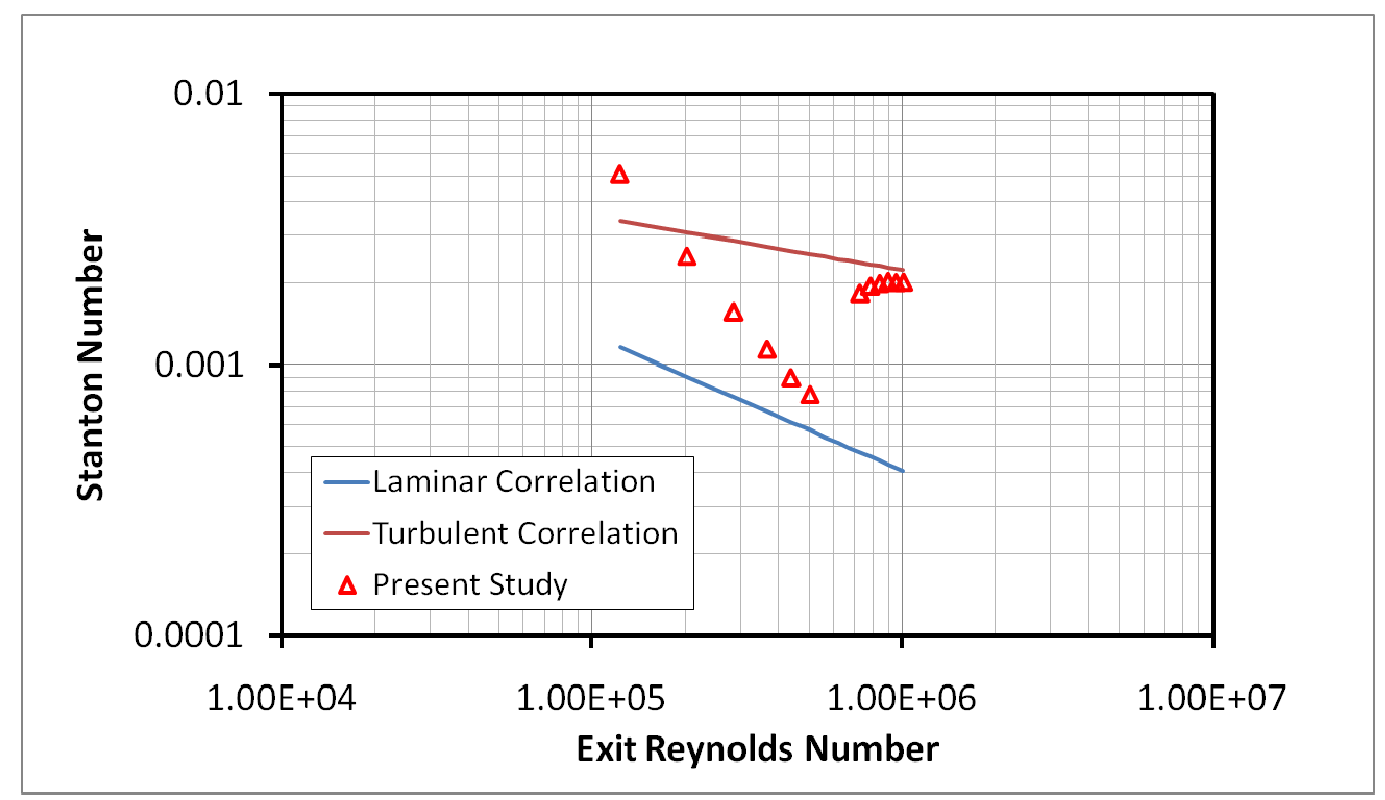

Figure 9: $\mathrm{SS} \mathrm{Mex}=0.85 \mathrm{BR}=2.0$ data compared with flat plate correlations

\section{Comparison with Showerhead-Only Vane}

Figure 10 shows a film cooling effectiveness comparison at $\mathrm{Mex}=0.85, \mathrm{BR}=2.0$ of data from the present study with that of Nasir et al. [27]. Nasir et al. [27] presents data taken on a vane of the same profile as the present study with only LE showerhead film cooling.

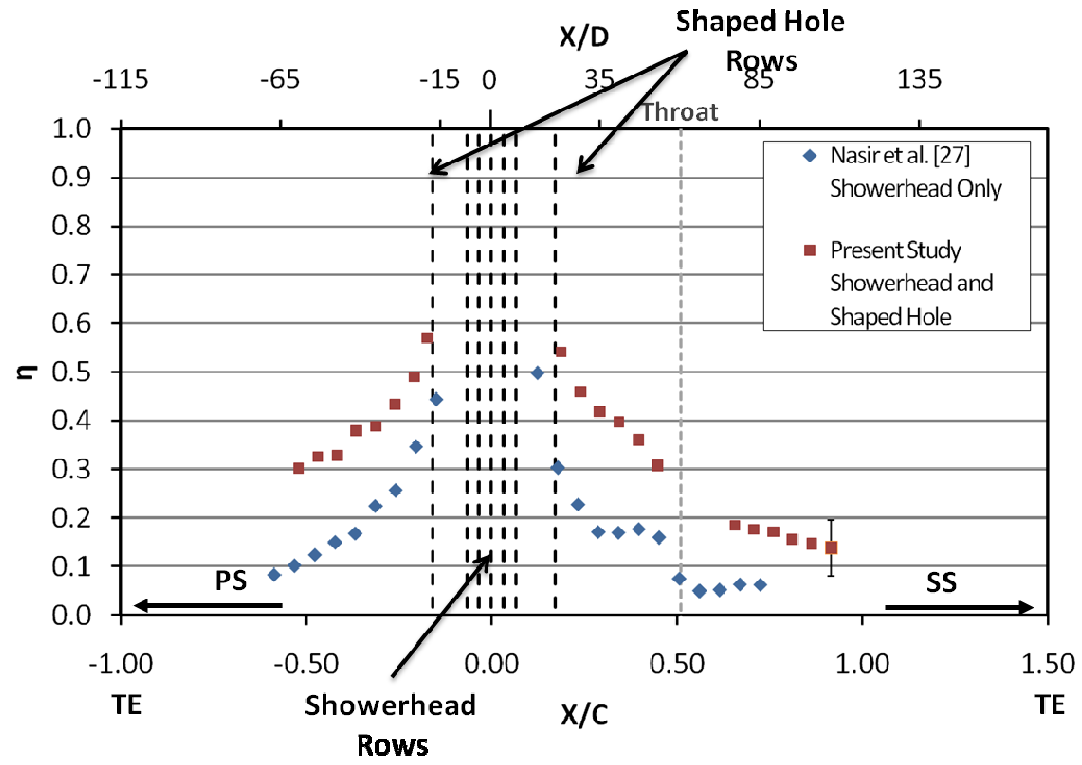

Figure 10: Film cooling effectiveness comparison at $\mathrm{Mex}=0.85, \mathrm{BR}=\mathbf{2 . 0}$ 
The comparison shows that the addition of shaped hole rows on the PS and SS has increased film effectiveness across the board. Shaped holes show a 2-2.5x improvement in effectiveness over showerhead only film cooling across the measurement range with only a 1.6x increase in coolant usage. It should also be noted that the shaped holes hold higher effectiveness values farther downstream than the showerhead rows. This is to be expected with shaped holes as they have been shown to diffuse less rapidly with streamwise distance than cylindrical hole cooling. One particular area of interest for both studies has been $0.3>\mathrm{X} / \mathrm{C}>0.50$. In this region the showerhead only data shows an effectiveness plateau, while the showerhead and shaped hole vane shows a sharp effectiveness decrease. Nasir et al. [27] attributed the effectiveness plateau to high values of acceleration in this region. High acceleration could have a laminarizing effect on the boundary layer, resulting in delayed film diffusion and the effectiveness plateau seen in the figure. This plateau then decays around the throat where the boundary layer transitions to full turbulence. Based on the present findings, the high acceleration in the region does not appear to have as significant an effect on shaped hole injection.

Figure 11 shows a comparison of Nusselt number between data from Nasir et al. [27] at Mex $=0.76, \mathrm{BR}=2.0$ and the present study at $\mathrm{Mex}=0.85$ and $\mathrm{BR}=2.0$. The first noticeable feature of this plot is considerably higher heat transfer in the near shaped hole region. This may be due to increased mixing and local turbulence directly at the injection site. However, on the SS downstream of injection, Nusselt number values drop below that of the showerhead case, showing what appears to be delayed transition as compared to the showerhead-only data. The exact reason this is occurring is not yet know, further research must be done on the subject to determine the cause. 


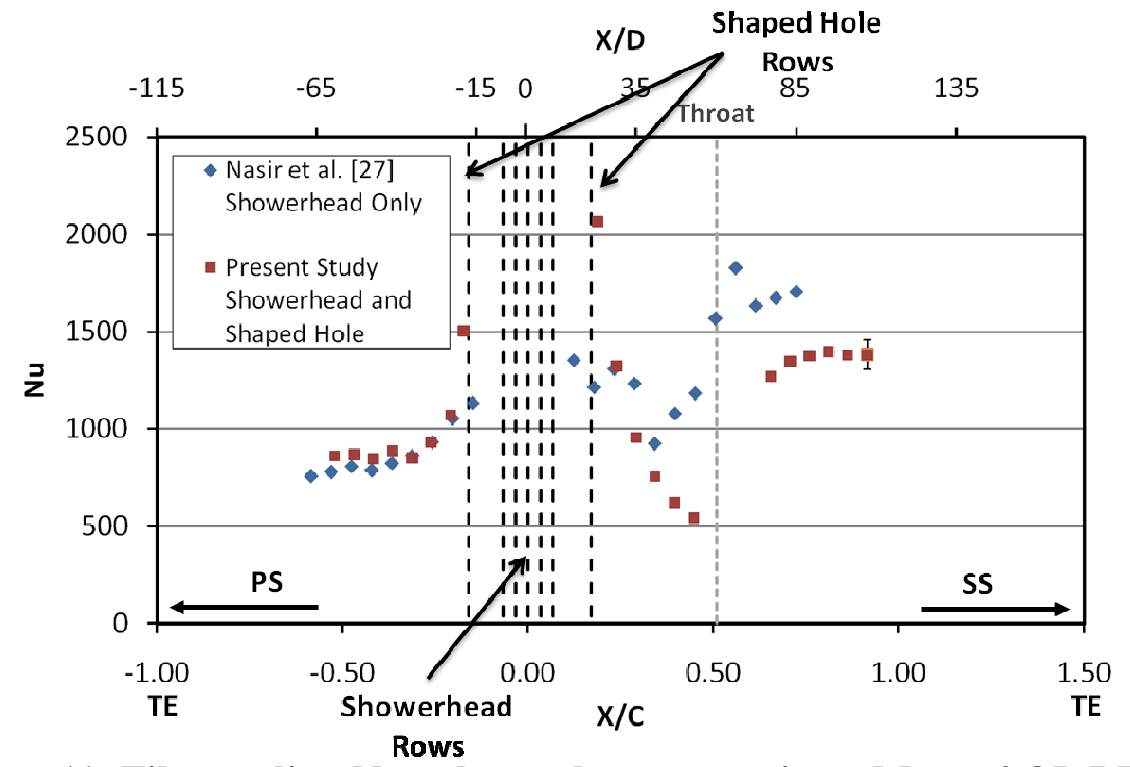

Figure 11: Film cooling Nusselt number comparison, $\mathrm{Mex}=\mathbf{0 . 8 5}, \mathrm{BR}=\mathbf{2 . 0}$

\section{Effect of Exit Mach Number on Film Effectiveness}

Figures 12, 13, and 14 highlight the effect of increasing exit Mach/Reynolds number on film effectiveness distributions. Increasing exit Mach number for all three BR cases results in increases in film effectiveness. An increasing trend in film effectiveness with increasing Mach/Reynolds number has been shown previously in literature for showerhead injection by Mehendale and Han [37].

The trend of increasing BR resulting in increased effectiveness is more apparent on the PS for $\mathrm{BR}=1.5$ and 1.0. On the SS, exit Mach numbers of 0.85 and 1.0 show only very small differences for the three BR cases. However, data taken at Mex $=0.60$ shows faster effectiveness decay. This may be due to uneven local velocity differences between the three cases resulting in more similar diffusion for the higher exit Mach numbers. While these two cases are sonic or near sonic in this region of the SS, the surface Mach numbers for the Mex $=0.60$ case are considerably lower. Lower surface velocities may change how the coolant jet interacts with the boundary layer, possibly causing more mixing effects resulting in faster diffusion. The trend of faster SS effectiveness decay at Mex $=0.6$ is seen at $\mathrm{BR}=1.5$ and 2.0 conditions. 


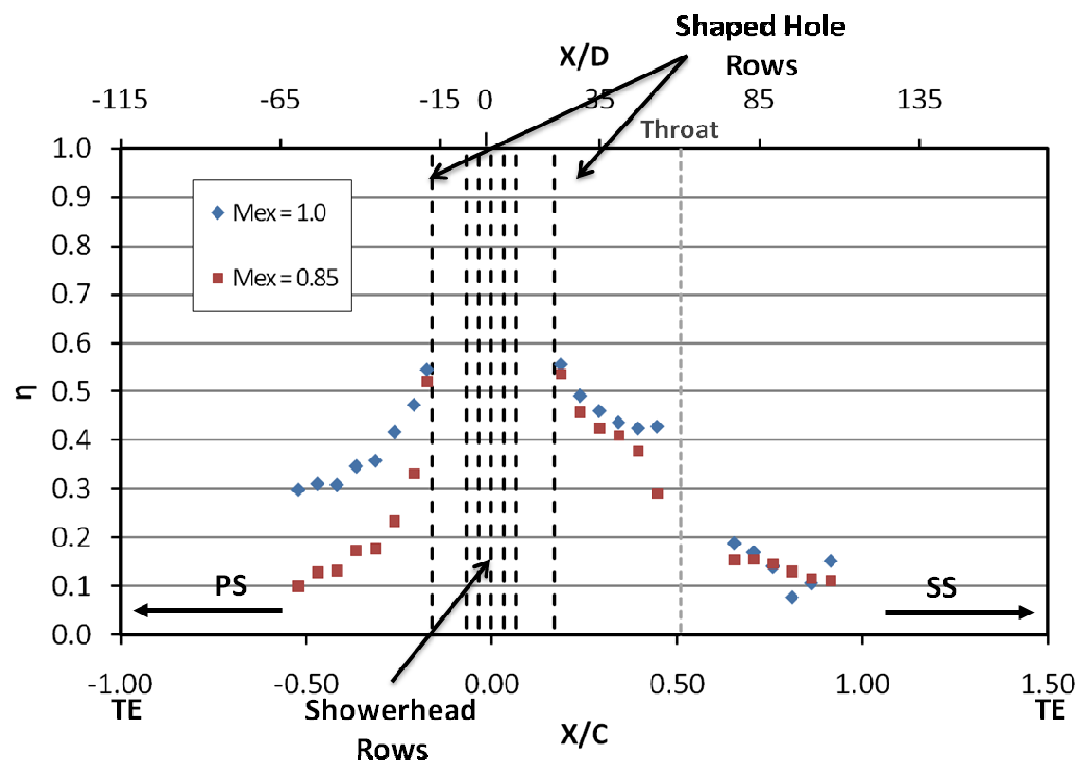

Figure 12: Effect of exit Mach number on film effectiveness distribution, $B R=1.0$

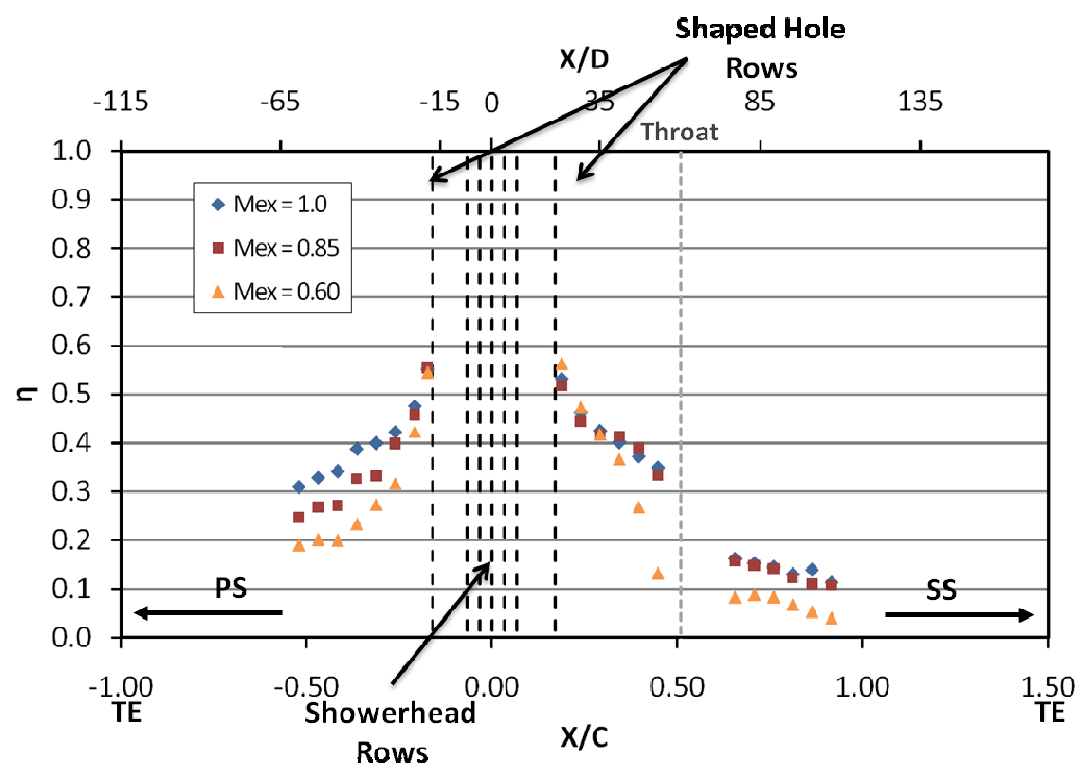

Figure 13: Effect of exit Mach number on film effectiveness distribution, $B R=1.5$ 


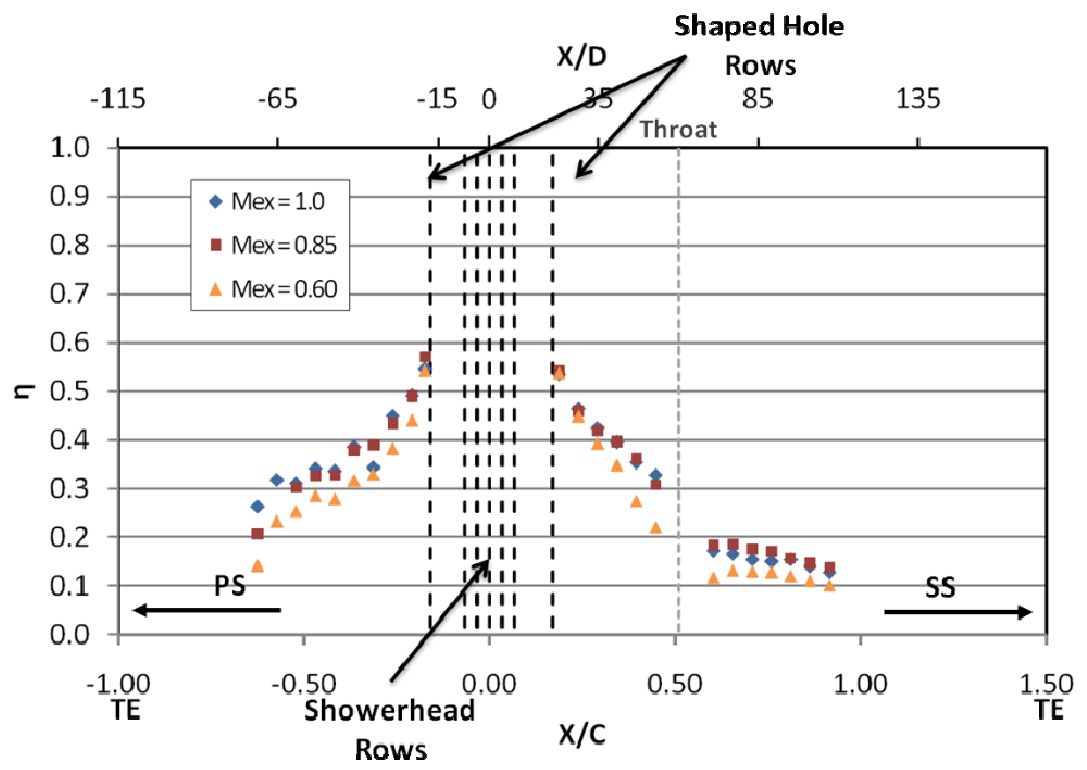

Figure 14: Effect of exit Mach number on film effectiveness distribution, $B R=2.0$

\section{Effect of Blowing Ratio on Film Effectiveness}

Figures 15, 16, and 17 highlight the effect of increasing blowing ratio on film effectiveness distributions.

For Mex $=0.85$, an increase in blowing ratio has the effect of increasing film effectiveness. This trend is considerably more apparent on the PS than the SS. This may be due (in part) to differing blowing ratios at the PS and SS shaped hole rows as a result of the vane's single plenum design. This type of trend was also mirrored in Nasir et al. [27] where a larger change in PS effectiveness was also observed. It also appears that on the pressure side, showerhead film cooling is dominating at lower blowing ratios. This can be seen in the more rapid decay of film effectiveness at BR $=1.0$. This type of trend was noted by Zhang et al. [18] in their PS-only study. At higher blowing ratios, the shaped holes start to dominate cooling, carrying effectiveness farther downstream.

On the PS of the vane, the BR $=1.0$ case tends to be noticeably lower than the other two cases. This is not the case for the SS side: for Mex $=0.85$, the SS effectiveness distribution shows little change with regard to changing blowing ratio, for Mex $=1.0$, the SS effectiveness actually shows higher effectiveness values at lower blowing ratios. Nasir et al. [27] showed this 
trend at Mex = 1.0 as well, and attributed it to the beginnings of jet liftoff at the higher blowing ratios combined with increased momentum of the freestream resulting in faster film diffusion.

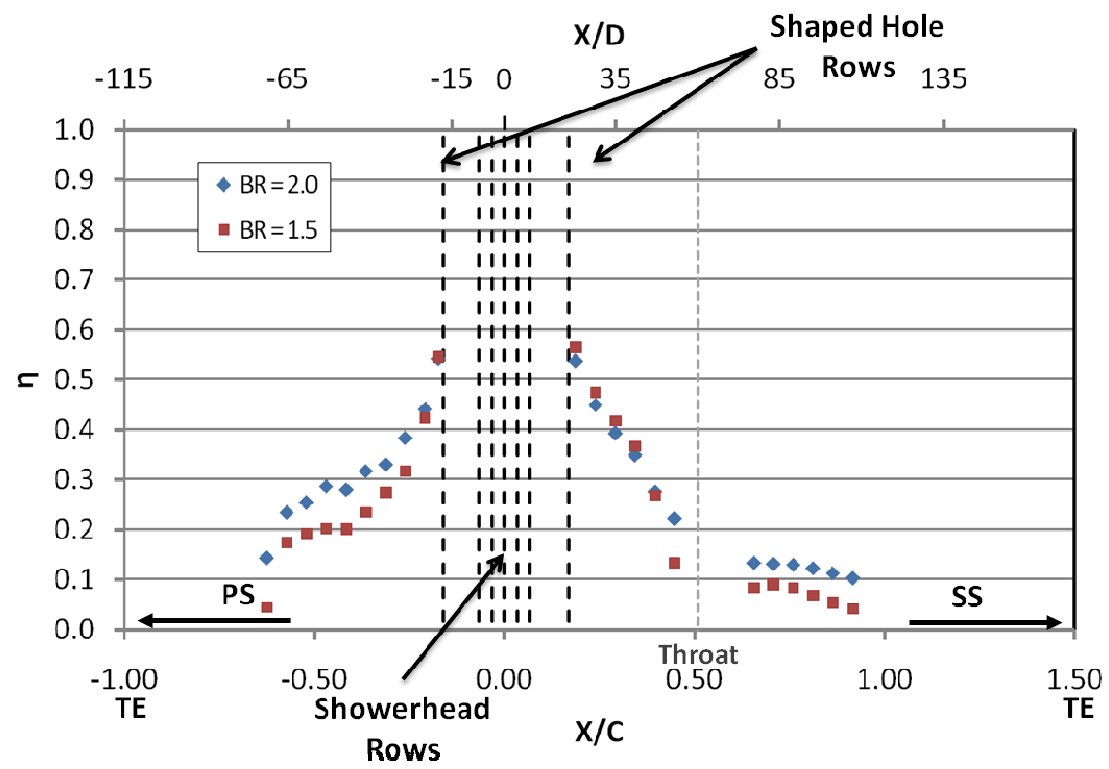

Figure 15: Effect of blowing ratio on film effectiveness, $M e x=0.60$

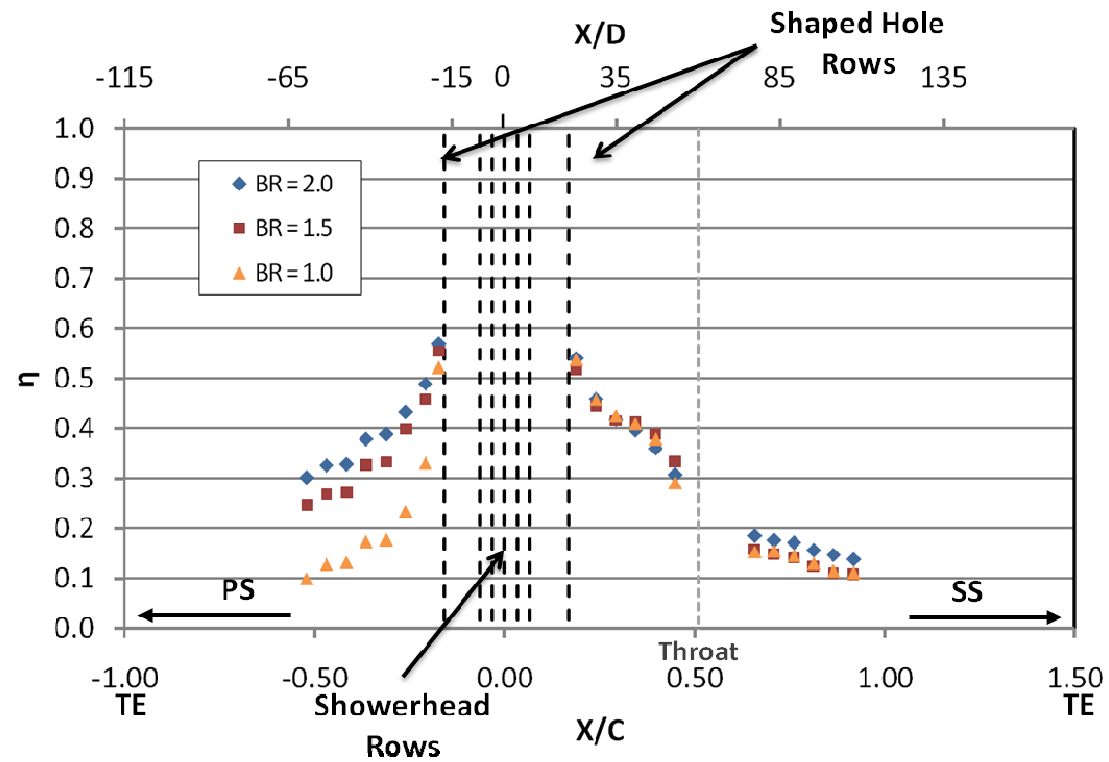

Figure 16: Effect of blowing ratio on film effectiveness, $M e x=0.85$ 


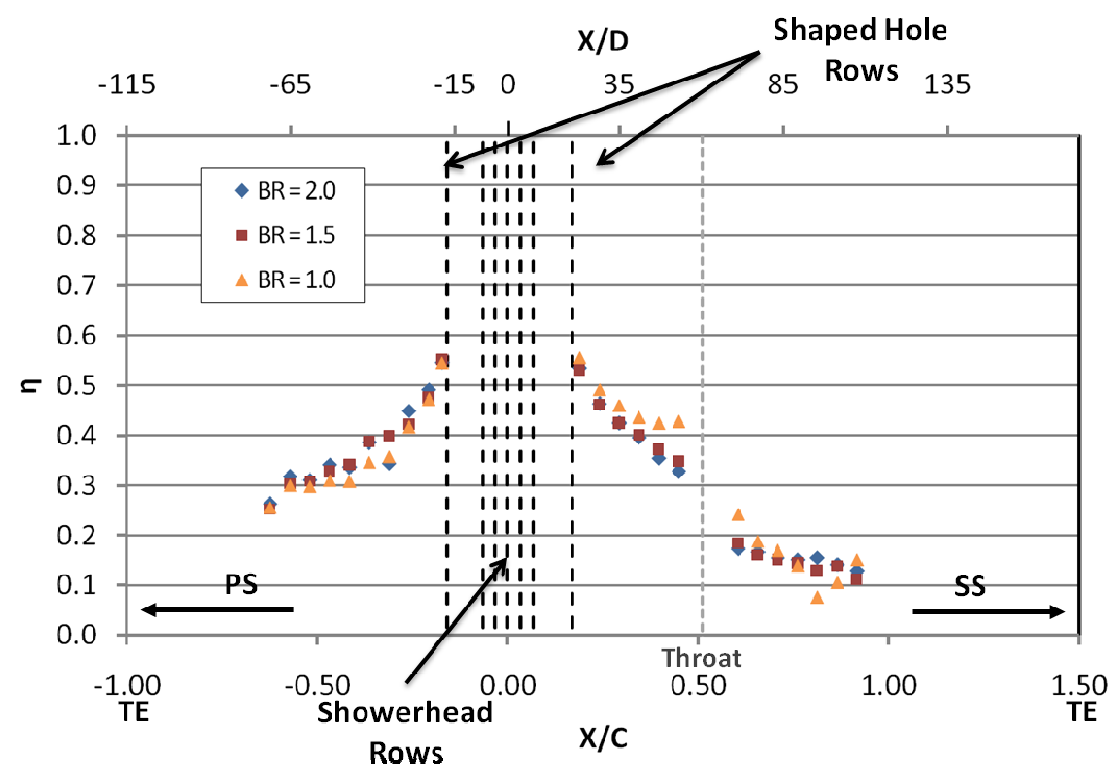

Figure 17: Effect of blowing ratio on film effectiveness, $M e x=1.0$

\section{Effect of Exit Mach Number on Nusselt Number}

Figures 18, 19, and 20 show the effect of increasing exit Mach number on Nusselt number for the three blowing ratio conditions tested.

Increasing exit Mach number for all blowing ratios has the apparent effect of augmenting Nusselt number on both the PS and SS of the measurement vane. A trend of increasing Nusselt number with increasing Mach number has been shown by Nasir et al. [27] as well as others such as such as Reiss and Bölcs [38] and Abuaf et al. [39]. On the SS, there is a discrepancy between the $\mathrm{Mex}=0.60$ data and the other two data sets at $\mathrm{BR}=1.5$ and 2.0. For Mex $=0.85$ and 1.0, Mach numbers at and near the throat are greater than one, and are very near sonic for much of the SS. This is not the case for Mex $=0.60$, and could explain why the Mex $=0.85$ and 1.0 results look more similar. Finally, the region where transition occurs does not appear to be effected by change in Mach/Reynolds number for any of the blowing ratio cases. For all three data sets transition is occurring in approximately the same region just upstream of the throat, and is identified by the sharp jump in Nusselt number seen on the SS on all three plots. A lack of change in transition region with changing exit Mach number is consistent with the findings of Nasir et al. [27] on the showerhead-only vane. Also of note is that the Nusselt number 
augmentation due to increasing blowing ratio can be tracked from plot to plot, and is increasing with increasing blowing ratio.

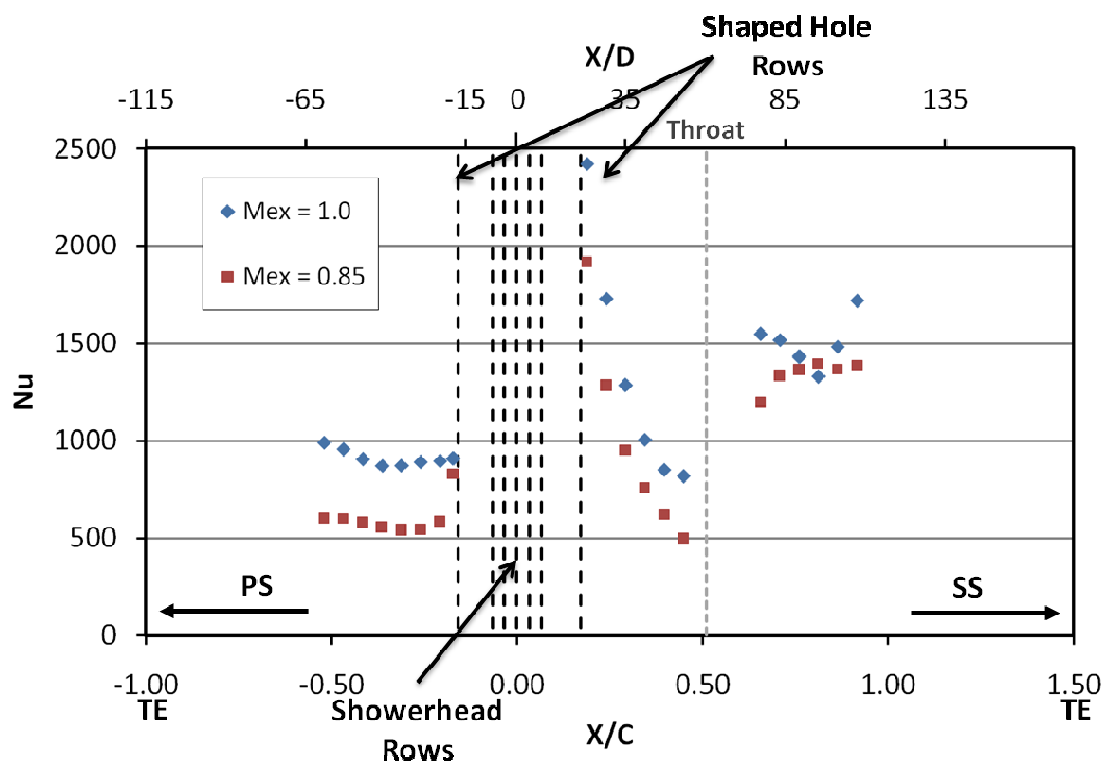

Figure 18: Effect of exit Mach number on Nusselt number distribution, $B R=1.0$

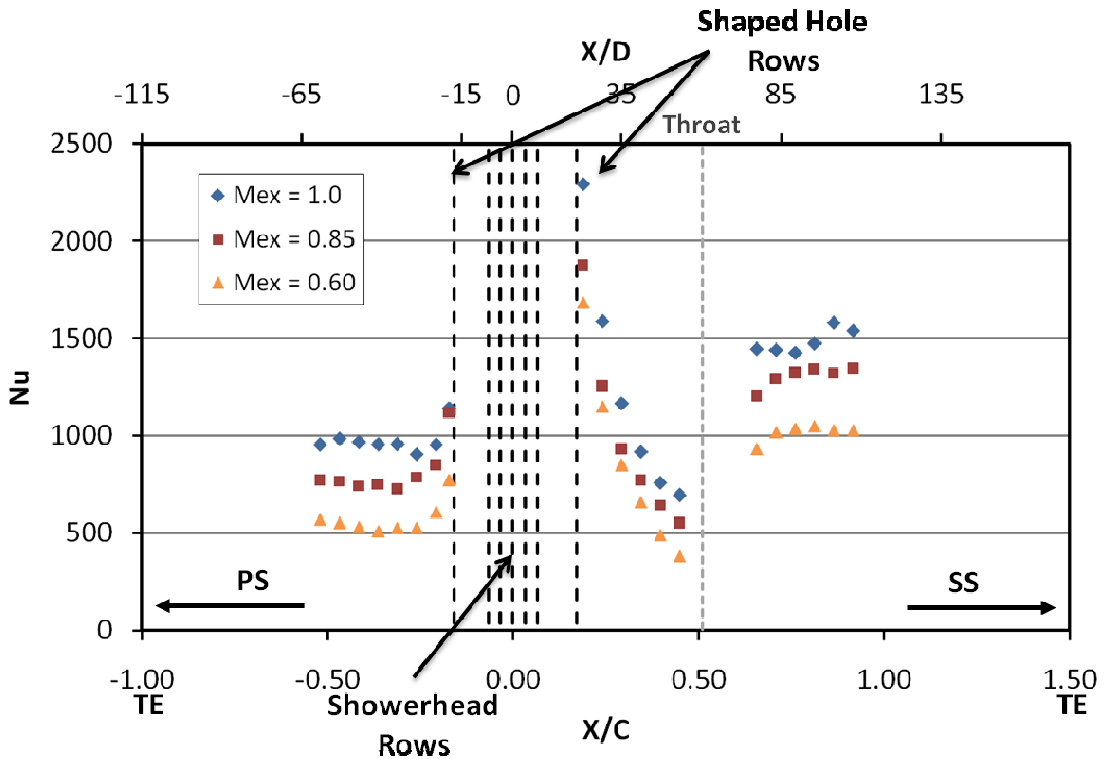

Figure 19: Effect of exit Mach number on Nusselt number distribution, $B R=1.5$ 


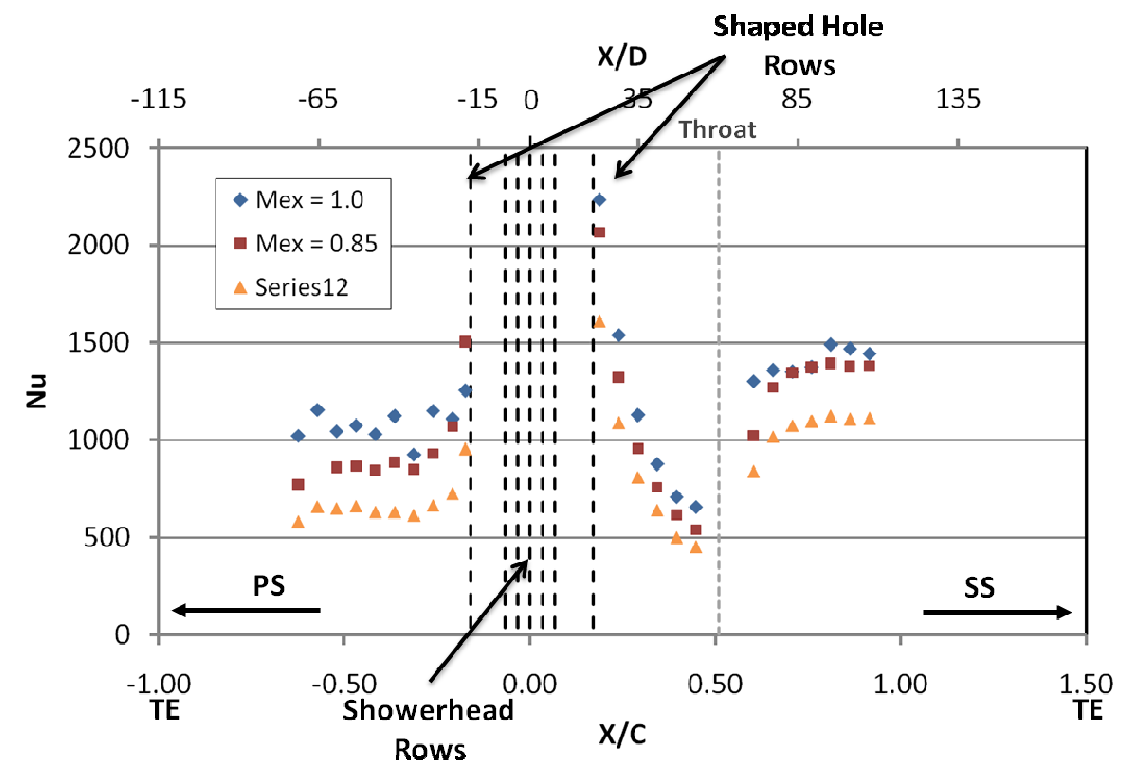

Figure 20: Effect of exit Mach number on Nusselt number distribution, $B R=2.0$

\section{Effect of Blowing Ratio on Nusselt Number}

Figures 21, 22, and 23 show the effect of blowing ratio on Nusselt number for the three exit Mach numbers tested in this study. For all three exit Mach number cases, Nusselt number shows an increasing trend on the PS. For Mex $=1.0$ and 0.60 the Nusselt number augmentation due to blowing ratio is considerably less obvious on the PS. This may be due in part to smaller changes in film effectiveness distribution for these cases.

The SS also shows little change for all three cases, most likely due to lack of significant change in effectiveness distribution in the region. This may be a result of lower blowing ratio changes from the SS shaped holes due to the single-plenum coolant feed design discussed earlier. On the PS, a trend of increasing Nusselt number with increasing blowing ratio is observed. Nusselt number augmentation as a result of higher blowing ratios is generally a result of increased local turbulence due to coolant injection and mixing. This trend has been seen elsewhere in literature such as Arts et al. [40] and Ekkad et al. [41] to name two. As was the case with varied exit Mach number, the location of boundary layer transition does not appear to change with blowing ratio. 


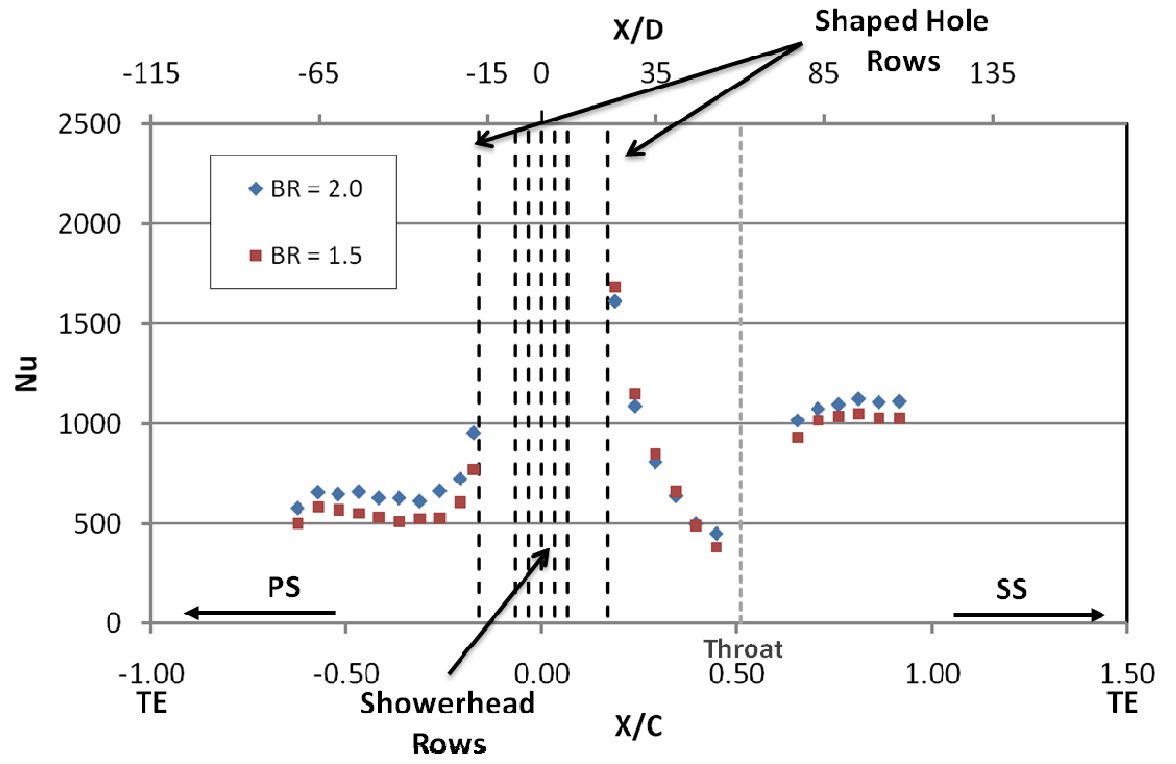

Figure 21: Effect of blowing ratio on Nusselt Number distribution, $M e x=0.60$

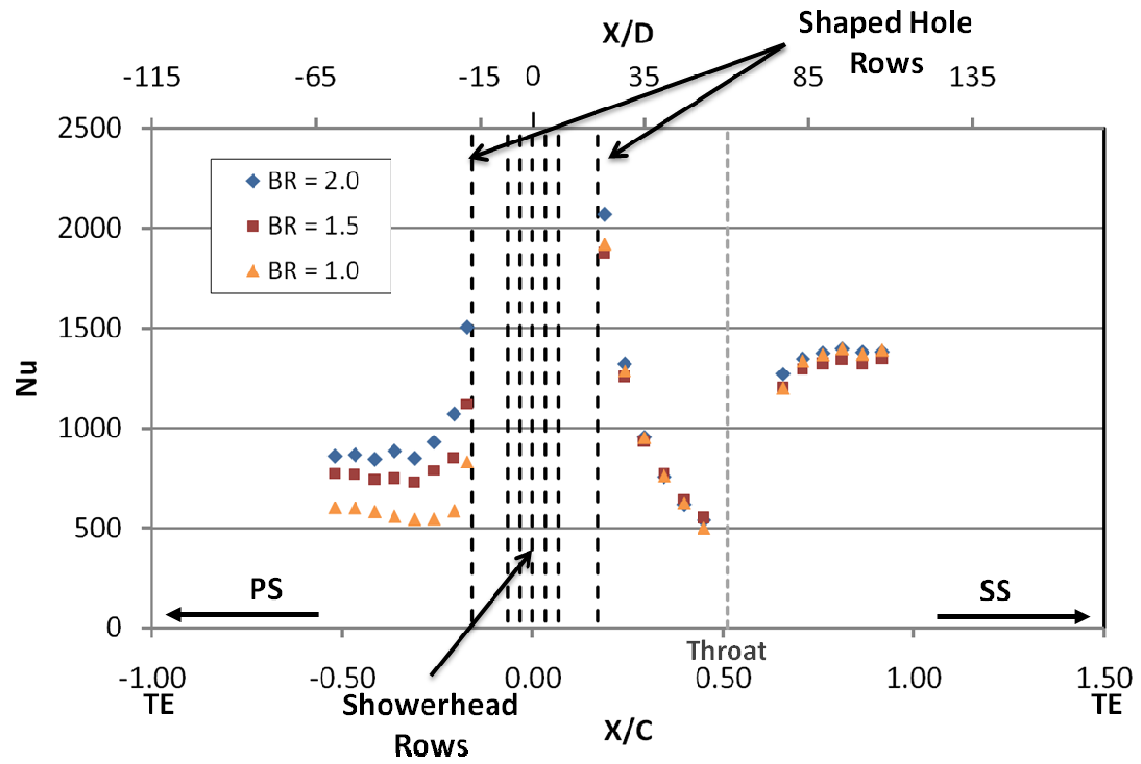

Figure 22: Effect of blowing ratio on Nusselt number distribution, $\mathrm{Mex}=0.85$ 


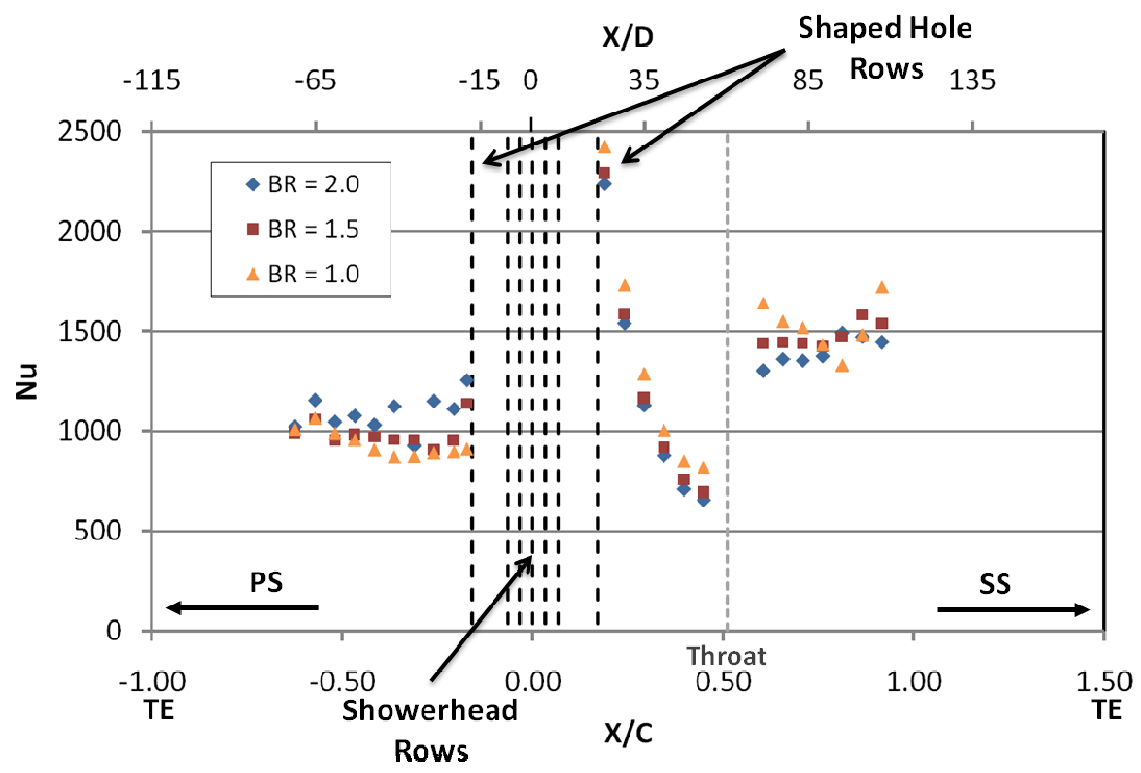

Figure 23: Effect of blowing ratio on Nusselt number distribution, Mex $=\mathbf{1 . 0}$

\section{NHFR Comparison}

Net heat flux reduction is a measure by which the overall film cooling performance of a film cooling design can be evaluated. It serves to show the relation between film cooling effectiveness and heat transfer by quantifying the reduction in absorbed heat effected by a particular film cooling design. Net heat flux reduction is defined below in equation 13.

$$
N H F R=1-\frac{q^{\prime \prime}}{q_{0}^{\prime \prime}}=1-\frac{h}{h_{0}}\left(1-\frac{\eta}{\phi}\right)
$$

In this equation $\phi$ refers to the overall film cooling effectiveness defined as in equation 14 .

$$
\phi=\frac{T_{w}-T_{r}}{T_{c}-T_{r}}
$$

This value is assumed to be between 0.5 and 0.7 according to Mehendale and Han [37]. A value in the middle of this range (0.6) will be used for NHFR analysis, this value has been used by Mehendale and Han [37], Drost et al. [42], and Nasir et al. [27] for high speed cascade studies. Heat transfer coefficient is normalized by heat transfer coefficient data taken by Nasir et al. [27] on a solid, uncooled vane without cooling holes in the same facility. This method was also used 
by Mehendale and Han [37] to normalize heat transfer coefficient. Based on the definition in equation 13, NHFR values that are close to unity imply that film cooling has a positive effect, reducing the heat absorbed by the surface. Zero or negative values of NHFR imply that film cooling is either totally ineffective, or has a detrimental effect on surface heat absorption respectively.

Figure 24 compares NHFR data recorded by Nasir et al. [27] on a showerhead-only film cooled vane using the same transient TFG technique as the present study. This figure illustrates the purpose of NHFR data in comparing two film cooling designs. As was the case with film effectiveness, the showerhead and shaped hole film cooled vane shows higher film cooling performance across the entire measurement surface with NHFR values an average of 2.6x higher across the measurement surface. Similar Nusselt number values combined with film effectiveness values 2-2.5x that of Nasir et al. [27] result in very large NHFR increases on the PS. On the SS, lower heat transfer augmentation from shaped hole film cooling results in slightly smaller gains over the showerhead-only case. However, the comparison supports the findings of the film effectiveness comparison: that film cooling performance is greatly improved downstream of the leading edge by adding shaped holes on the PS and SS. Again, this average 2.6x NHFR increase occurs with only a 1.6x increase in the required coolant mass flow.

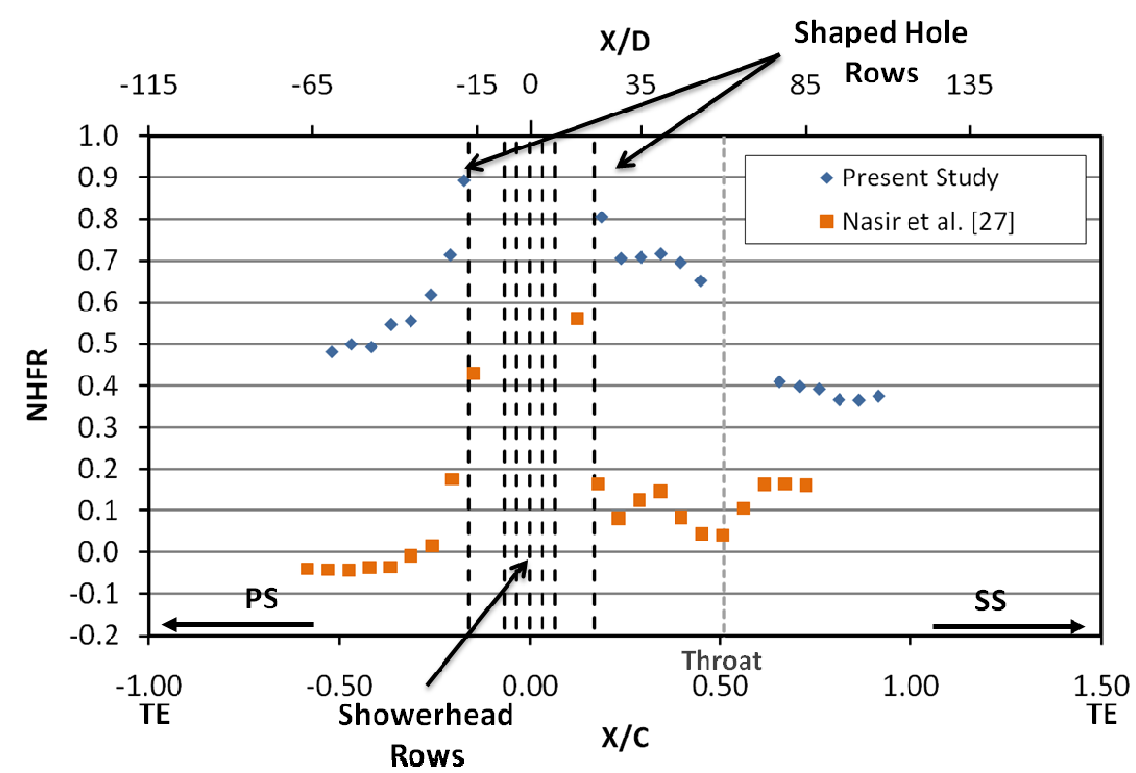

Figure 24: Comparison of NHFR from Nasir et al. [27] with the present study 


\section{Conclusions}

Film cooling performance tests were conducted for three exit Mach number/Reynolds number combinations: 1.0/1,400,000; 0.85/1,150,000; and 0.60/850,000. At exit Mach numbers of 1.0 and 0.85 three blowing ratio conditions were tested: $\mathrm{BR}=1.0,1.5$, and 2.0. At exit Mach number 0.60 two blowing ratio conditions were tested: $\mathrm{BR}=1.5$ and 2.0. All tests were performed at high freestream turbulence levels with inlet turbulence intensity of $12 \%$ and turbulence length scale normalized by leading edge diameter of 0.28 . Vane surface film cooling effectiveness and net heat flux reduction distributions were presented and compared with literature. The chief conclusions of the study are as follows:

Film cooling effectiveness data compared well in both level and trend with existing shaped hole literature at similar conditions. Stanton number compared favorably with analytical laminar and turbulent flat plate boundary layer solutions, with expected trends reported on the PS and SS.

The addition of shaped hole rows downstream of showerhead injection on both the PS and SS of the vane resulted in film effectiveness levels averaging $2-2.5 x$ those of a showerhead only film cooled vane. The addition of shaped hole rows brought about this large increase in effectiveness while only increasing coolant mass flow by 1.6x. The addition of shaped holes was also shown to augment heat transfer considerably in the near hole region on the SS and PS.

A comparison of NHFR between a showerhead only and combined showerhead and shaped hole film cooled vane showed that the addition of a single row of shaped holes to both the PS and SS of the vane resulted in considerably increased NHFR (2.6x the value of showerhead-only NHFR) downstream of the holes. This analysis showed that the addition of shaped holes reduced the amount of heat absorbed by the PS and SS over showerhead-only injection with a 1.6x increase in coolant mass flow required.

For constant Mach number, increasing blowing ratio showed increases in film effectiveness and heat transfer augmentation on the PS. Little significant increase in film effectiveness or heat transfer augmentation was seen in SS data for varying blowing ratio. 
For constant blowing ratio, film cooling effectiveness was shown to have a slower rate of decay with increasing Mach number. This was especially true when injection locations with subsonic Mach numbers were compared with locations with sonic or greater Mach numbers. 


\section{References}

[1] Goldstein, R. J., Eckert, E. R. G., and Burggraf, F., 1974, "Effects of Hole Geometry and Density on ThreeDimensional Film Cooling," Int. J. Heat Mass Transfer, 17, pp. 595-607.

[2] Schmidt, D., Sen, B., and Bogard, D., 1996, "Film Cooling with Compound Angle Holes: Adiabatic Effectiveness," ASME J. Turbomachinery, 118, pp. 807-813

[3] Gritsch, M., Schulz, A., and Wittig, S., 1998, "Heat Transfer Coefficients Measurements of Film-Cooling Holes With Expanded Exits," IGTI Conference, Stockholm, Paper 98-GT-28.

[4] Y. Yu, C.H. Yen, T.I.P. Shih, M.K. Chyu and S. Gogineni, 2002, "Film cooling effectiveness and heat transfer coefficient distributions around diffusion shaped holes," ASME J. Heat Transfer, 124, pp. 820-827.

[5] Bell, C. M., Hamakawa, H., Ligrani, P. M., 2000, "Film Cooling From Shaped Holes," ASME J. Heat Transfer, 122, pp. 224-232.

[6] Dittmar, J., Schulz, A., Wittig, S., 2003, “Assessment of Various Film-Cooling Configurations Including Shaped and Compound Angle Holes Based on Large-Scale Experiments," ASME J. Turbomachinery, 125, pp. 57-64

[7] Yuen, C. H. N., Martinez-Botas, R. F., and Whitelaw, J. H., 2001, "Film Cooling Effectiveness Downstream of Compound and Fan-Shaped Holes," IGTI Turbo Expo, New Orleans, Paper 2001-GT-0131.

[8] Lu, Y., Dhungel, A., Ekkad, S. V., Buker, R. S., 2009, "Effect of Trench Width and Depth on Film Cooling from Cylindrical Holes Embedded in Trenches," ASME J. Turbomachinery, 131, pp. 1-13

[9] Dhungel, A., Lu, Y., Phillips, W., Ekkad, S. V., Heidmann, J., 2009, "Film Cooling From a Row of Holes Supplemented with Antivortex Holes," ASME J. Turbomachinery, 131, pp. 1-13

[10] Witting, S., Schulz, A., Gritsch, M., Thole, K. A., 1996, “Transonic Film-Cooling Investigations: Effects of Hole Shapes and Orientations," IGTI Turbo Expo, Birmingham, UK, Paper 1996-GT-222.

[11] Thole, K. A., Gritsch, M., Schulz, A., Witting, S., 1998, "Flowfield Measurements for Film-Cooling Holes With Expanded Exits," ASME J. Turbomachinery, 120, pp. 327-336

[12] Saumweber, C., Schulz, A., 2004, "Interaction of Film Cooling Rows: Effects of Hole Geometry and Row Spacing on the Cooling Performance Downstream of the Second Row of Holes," ASME J. Turbomachinery, 126, pp. 237-246

[13] Saumweber, C., and Schulz, A., 2003, "Interaction of Film Cooling Rows: Effects of Hole Geometry and Row Spacing on the Cooling Performance Downstream of the Second Row of Holes,' IGTI Turbo Expo, Atlanta, Paper GT2003-38195.

[14] Colban, W., Gratton, A., Thole, K. A., Haendler, M., 2005, "Heat Transfer and Film-Cooling Measurements on a Stator Vane with Fan-Shaped Cooling Holes," IGTI Turbo Expo, Reno-Tahoe, Paper GT2005-68258.

[15] Colban, W., Thole, K. A., Haendler, M., 2007, "Experimental and Computational Comparisons of FanShaped Film Cooling on a Turbine Vane Surface," ASME J. Turbomachinery, 129, pp. 23-31

[16] Chappell, J., Ligrani, P., Sreekanth, S., Lucas, T., 2008, "Suction-Side Gill-Region Film Cooling: Effects of Hole Shape and Orientation on Adiabatic Effectiveness and Heat Transfer Coefficient," IGTI Turbo Expo, Berlin, Paper GT2008-50798. 
[17]Furukawa, T., Ligrani, P., 2002, “Transonic Film Cooling Effectiveness from Shaped Holes on a Simulated Turbine Airfoil," AIAA J. Thermophysics and Heat Transfer, 16, pp. 228-237

[18]Zhang, L., Pudupatty, R., 2000, "The Effects of Injection Angle and Hole Exit Shape on Turbine Nozzle Pressure Side Film-Cooling,” IGTI Turbo Expo, Munich, Paper 2000-GT-247.

[19]Zhang, L., Moon, H. K., 2008, “The Effect of Wall Thickness on Nozzle Suction Side Film Cooling," IGTI Turbo Expo, Berlin, Paper GT2008-50631.

[20] Schnieder, M., Parneix, S., von Wolfersdorf, J., 2003, "Effect of Showerhead Injection on Superposition of Multi-Row Pressure Side Film Cooling with Fan Shaped Holes," IGTI Turbo Expo, Atlanta, Paper GT2003-38693.

[21] Thurman, D. R., Poinsatte, P. E., Heidmann, J. D., 2008, "Heat Transfer Measurements for a Film Cooled Turbine Vane Cascade," IGTI Turbo Expo, Berlin, Paper GT2008-50651

[22] Guo, S. M., Lai, C. C., Jones, T. V., Oldfield, M. L. G., Lock, G. D., Rawlinson, A. J., 1998, “The application of thin-film technology to measure turbine-vane heat transfer and effectiveness in a film-cooled, engine-simulated environment," Int. J. Heat and Fluid Flow, 19, pp. 594-600

[23] Sargison, J. E., Guo, S. M., Oldfield, M. L. G., Lock, G.. D., Rawlinson, A. J., 2002, “A Converging SlotHole Film-Cooling Geometry—Part 2: Transonic Nozzle Guide Vane Heat Transfer and Loss,” ASME J. Turbomachinery, 124, pp. 461-471

[24]Reagle, C. J., Newman, A., Xue, S., Ng, W., Ekkad, S., Moon, H. K., Zhang, L., 2010, “A Transient Infrared Technique for Measuring Surface and Endwall heat Transfer in a Transonic Turbine Cascade," IGTI Turbo Expo, Glasgow, Paper GT2010-22975

[25] Bolchoz, T., Nasir, S., Reagle, C., Ng, W.F., and Moon, H.K., 2009, “An Experimental Investigation of Showerhead Film Cooling Performance In A Transonic Vane Cascade At Low and High Freestream Turbulence," IGTI Turbo Expo, Orlando, Paper GT2009-59796.

[26] Nasir, S., Carullo, J.S., Ng, W.F., Thole, K.A., Wu, H., Zhang, L.J., and Moon, H.K., 2007, "Effects of Large Scale High Freestream Turbulence, and Exit Reynolds Number on Turbine Vane Heat Transfer in a Transonic Cascade," ASME J. Turbomachinery, 131, pp.021021-1 to -11.

[27] Nasir,S., Bolchoz, T., Ng, W.F., Zhang, L.J., Moon, H.K., Anthony, R.J., 2008, “Showerhead Film Cooling Performance of a Turbine Vane in a Transonic Cascade," ASME IMECE 2008, Paper 66528.

[28] Doorly, J.E., Oldfield, M.L.G., 1987, “The Theory of Advanced Multi-Layer Thin Film Heat Transfer Gages," Int. J. Heat and Mass Transfer, 30, pp. 1159-1168.

[29] Joe, C.R., 1997, "Unsteady Heat Transfer on the Turbine Research Facility at Wright Laboratory," Ph.D. Dissertation, Syracuse University.

[30] Cress, R.D., 2006, “Turbine Blade Heat Transfer Measurements in a Transonic Flow Using Thin film Gages," Master's Thesis, Virginia Polytechnic Institute and State University.

[31] Popp, O., Smith, D.E., Bubb, J.V., Grabowski, H.C., Diller, T.E. Schetz, J.A., Ng. W.F., 2000, “An Investigation of Heat Transfer in a Film Cooled Transonic Turbine Cascade, Part II: Unsteady Heat Transfer," IGTI Turbo Expo, Berlin, Paper GT-2000-203. 
[32] Ekkad, S. V., Han, J. C., Du, H., 1998, "Detailed Film Cooling Measurements on a Cylindrical Leading Edge Model: Effect of Free-Stream Turbulence and Coolant Density," ASME J. Turbomachinery,120, pp. 799-807.

[33] Moffat, R. J., 1988, “Describing Uncertainties in Experimental Results,” Exp. Thermal and Fluid Science, 1, pp. 3-17.

[34] Brown, K.H., Coleman, H.W., and Steele, W.G., 1995, "Estimating Uncertainty Intervals for Linear Regression," AIAA-1995-0796.

[35] Incropera, F.P. and DeWitt, D.P., 2002, Fundamentals of Heat and Mass Transfer, 5th Ed., John Wiley and Sons, New York.

[36] Blair, M. F., 1983, “Influence of Free-Stream Turbulence on Turbulent Boundary Layer Heat Transfer and Mean Profile Development, Part I-Experimental Data,” ASME J. Heat Transfer, 105, pp. 33-40.

[37] Mehendale, A.B., Han, J.-C., 1993, "Reynolds number Effect on Leading Edge Film Effectiveness and Heat Transfer Coefficient," Int. J. Heat and Mass Transfer, 36, pp. 3723-3730.

[38] Reiss, H., Bölcs, A., 2000, “The Influence of the Boundary Layer State and Reynolds Number on Film Cooling and Heat Transfer on a Cooled Nozzle Guide Vane,” IGTI Turbo Expo, Berlin, GT-2000-205.

[39] Abuaf, N., Bunker, R., Lee, C. P., 1997, "Heat Transfer and Film Cooling Effectiveness in a Linear Airfoil Cascade," ASME J. Turbomachinery, 119, pp. 302-309

[40] Arts, T., Bourguignon, A.E., 1990, "Behavior of a Coolant Film with Two rows of Holes along the Pressure Side of a High Pressure Nozzle Guide Vane," ASME J. Turbomachinery, 112, pp. 512-520.

[41] Ekkad, S.V., Mehendale, A.B., Han, J.-C., Lee, C.P., 1997, “Combined Effect of Grid Turbulence and Unsteady Wake on Film Effectiveness and Heat Transfer Coefficient of a Gas Turbine Blade with Air and $\mathrm{CO}_{2}$ Film Injection,” ASME J. Turbomachinery, 119, pp. 594-600.

[42] Drost, U., Bölcs, A., 1999, “Investigation of Detailed Film Cooling Effectiveness and Heat Transfer Distribution on a Gas Turbine Airfoil," ASME J. Turbomachinery, 121, pp. 233-242. 


\section{Appendix A: Film Cooling Supply}

\section{Film Cooling Supply Plumbing}

Air is measured and supplied to the film cooled test section by way of a film cooling supply circuit. A picture of one section of this film cooling circuit can be seen in figure A-1. The circuit is fed by a large pressure tank in the corner of the transonic tunnel lab. This pressure tank is charged by a small compressor located outside the building. Air first flows through an on/off solenoid valve and than through an adjustable control valve before reaching the metering part of the circuit shown in figure A-1. After passing through the control valve, upstream total and static pressure is measured by a pitot probe and line total temperature is measured by a T-type thermocouple. Air then flows through an orifice meter where the static pressure difference across the orifice plate is measured. The static pressure difference across the orifice plate, along with the flow properties measured by the thermocouple and pitot probe, is used to calculate the coolant mass flow rate.

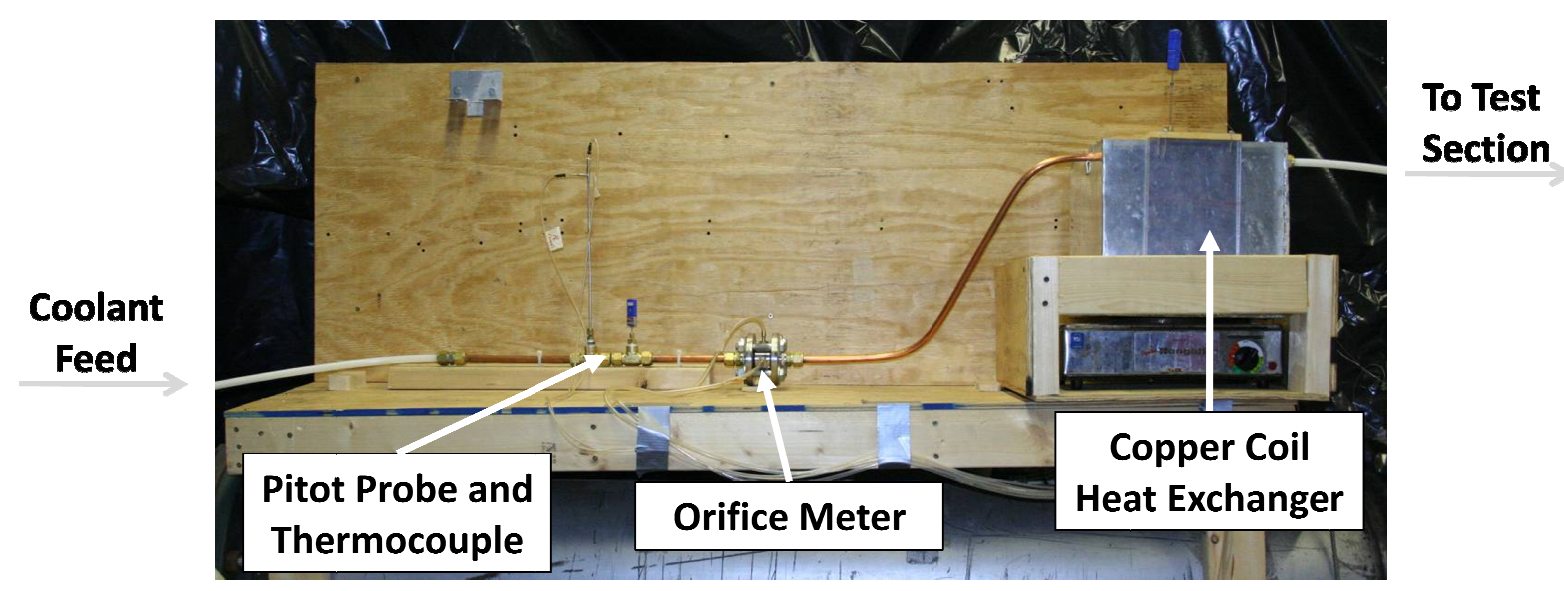

Figure A 1: Coolant supply circuit measurement section

After passing through the orifice meter, coolant flows into a copper-coil heat exchanger. For chilled coolant tests, this heat exchanger is moved closer to the test section and filled with about 1.5 " of liquid nitrogen, resulting in a coolant temperature of around $-40^{\circ} \mathrm{C}$. Coolant can also be heated using the heat exchanger, but for the purposes of this study coolant was either run at room temperature or chilled conditions. After passing through the heat exchanger, coolant is routed to the test vane by way of flexible plastic pipe. Coolant total and static pressure are 
measured directly at the plenum entrance with a pitot probe, and coolant temperature is again measured in the plenum with a T-type thermocouple.

\section{Blowing Ratio Calculation}

Blowing ratio is calculated using equation A-1:

$$
B R=\frac{\rho_{c} U_{c}}{\rho_{\infty} U_{\infty}}=\frac{\dot{m}_{c}}{A_{\text {holes }} \rho_{i} U_{i}}
$$

where $c$ subscripts refer to coolant conditions, $\infty$ subscripts refer to inlet conditions for showerhead and local conditions for shaped holes, and $i$ subscripts refer to inlet conditions. $A_{\text {holes }}$ is the combined cross-sectional area of all the holes being considered (in this case all of the showerhead holes, or all of the holes in a shaped hole row), and $m$ refers to mass flow rate.

To obtain coolant mass flow as referenced in equation A-1, the ideal mass flow rate for a row of holes is first calculated using equation A-2.

$$
\dot{m}_{c, \text { ideal }}=A_{c} P_{t, c}\left(\frac{P_{\infty, s}}{P_{t, c}}\right)^{\frac{\gamma+1}{2 \gamma}} \sqrt{\frac{2 \gamma}{(\gamma-1) R T_{t, c}}\left[\left(\frac{P_{t, c}}{P_{\infty, s}}\right)^{\frac{\gamma-1}{\gamma}}-1\right]}
$$

Actual mass flow rate is then calculated by multiplying equation A-2 by the discharge coefficient for the row of holes where blowing ratio is desired. Equation A-3 shows this relationship.

$$
\dot{m}_{c, \text { actual }}=C_{d} \times \dot{m}_{c, \text { ideal }}
$$


The fact that all seven rows of holes are fed off of the same plenum makes calculating blowing ratio for individual holes difficult. The common plenum design makes measuring the actual row mass flow rate impossible, so discharge coefficients must be used to determine the mass flow rate spit in the plenum. To determine the blowing ratio and corresponding mass flow rate for each row of holes, the discharge coefficient for each row must be measured at varying pressure ratios. Discharge coefficient for showerhead injection was able to be measured by performing tests on a showerhead-only vane. This was not possible for the shaped hole rows given that all of the coolant rows are fed off of a common plenum. For the shaped hole rows an assumed discharge coefficient of 0.82 was provided by Solar Turbines for use in the tests. 


\section{Appendix B: Thin Film Gauge Instrumentation}

\section{TFG Instrumentation Overview}

The gauges used in the study were manufactured by AFRL and provided by Dr. Richard Anthony. They are of a similar design to those used by Nasir [B-1], but have differences in construction that make them more delicate to install and allow for more sensitive measurements. These gages are more gold in color than previously used gages, and can be differentiated from older gages by measuring room temperature resistance. Previous gages measure anywhere from 50-70 Ohms, whereas the new gages will read from 80-120 Ohms at room temperature.

Before mounting, the gage sheets were trimmed to an appropriate size with a razor blade. To maximize the amount of useful data taken, the gage sheet was split into two sheets: one with 10 gages and another with 15 . These sheets were then mounted starting directly downstream of the shaped holes. The gage sheet was split, rather than being wrapped around the entire vane for two reasons: there was no good way to cut holes in the sheet that would match the exit profile of the shaped holes, and there was only room to fit one gage in between the showerhead and shaped hole injection locations. For these reasons the gage sheet was cut and one set of gages was applied to the SS while the other was applied to the PS. Gage coverage on the PS is from $0.173>\mathrm{X} / \mathrm{C}>-0.572$, and gage coverage on the $\mathrm{SS}$ is from $0.188<\mathrm{X} / \mathrm{C}<0.916$. The $\mathrm{SS}$ is instrumented with a sheet of 15 gages and the PS is instrumented with a sheet of 10 gages.

\section{TFG Installation and Wiring}

Before mounting, the resistance of each gage was checked with a digital multi-meter to ensure that the TFGs were all functioning properly. The Macor vane was placed in an assembly jig and its surface was thoroughly cleaned with isopropyl alcohol. Marks were then made on the

vane surface corresponding to the measurement centerline and the edges of the gage sheet to assist in proper mounting. Once the marks were finalized, the gage sheet was carefully applied to the vane surface starting at the shaped hole exits and proceeding downstream. A paper towel was run along the gage surface using a back and forth motion in the spanwise direction to ensure good adhesion and to press out air bubbles. When both sheets were applied the gage surfaces were cleaned with isopropyl alcohol, and the edges of the gage sheets were firmly seated by tracing along the edges using firm pressure from the back side of a fingernail. Once the TFGs 
were cleaned with alcohol, a strip of adhesive-backed Kapton sheet was wrapped over the leads of the TFGs and around the entire vane to help keep the leading edges of the TFG sheets from peeling at high Mach numbers. The TFGs applied to the vane and the extra Kapton strip can be seen in figure B-1.

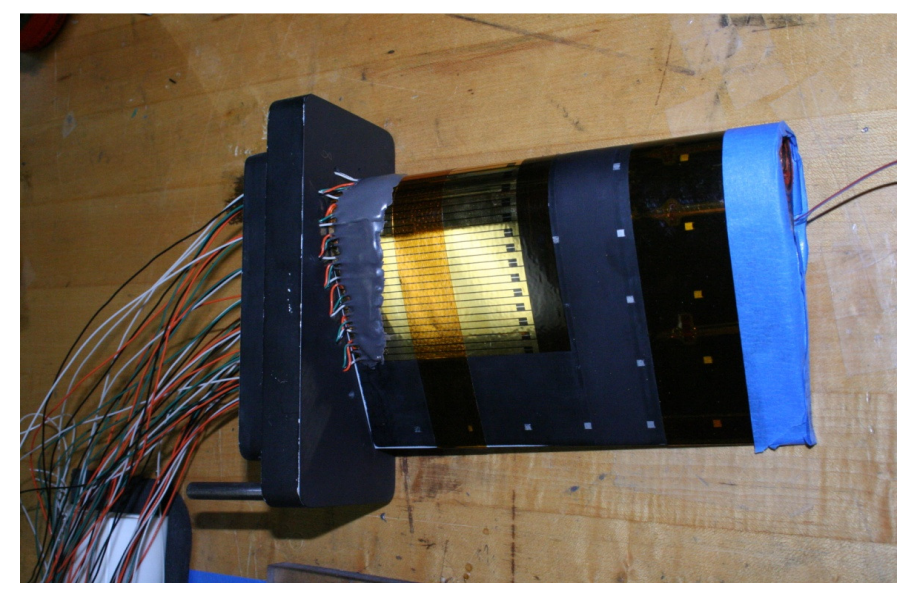

Figure B 1: Fully wired showerhead + shaped hole vane

Once the TFGs were applied to the vane, the task of soldering TFG leads could begin. A close up photo of soldered TFG leads can be seen in figure B-2. The procedure developed by Carullo [B-2] was used with some slight modifications. As mentioned earlier, the gages used in this study were found to be considerably more fragile than those used in past studies. As a result a lower soldering iron temperature and different soldering procedure was used. For these TFGs an iron temperature of $425^{\circ} \mathrm{F}$ is ideal using the following sequence to solder leads:

1. Strip and tin end of lead wire, do not attempt to tin gauge lead.

2. Apply flux to tinned lead wire and to gage surface

3. Melt a small amount of solder on iron tip so as to create a puddle

4. Place and hold lead wire on top of gage lead

5. Carefully bring solder puddle on end of iron into contact with gage lead and lead wire. Do not allow tip of soldering iron to touch gage lead or linger for more than 1-2 seconds. Doing so will result in solder joint failure.

6. Hold lead wire in place for a few seconds after soldering joint, test gage resistance to verify solder joint integrity. Figure B-3 shows what acceptable solder joints should look like. 


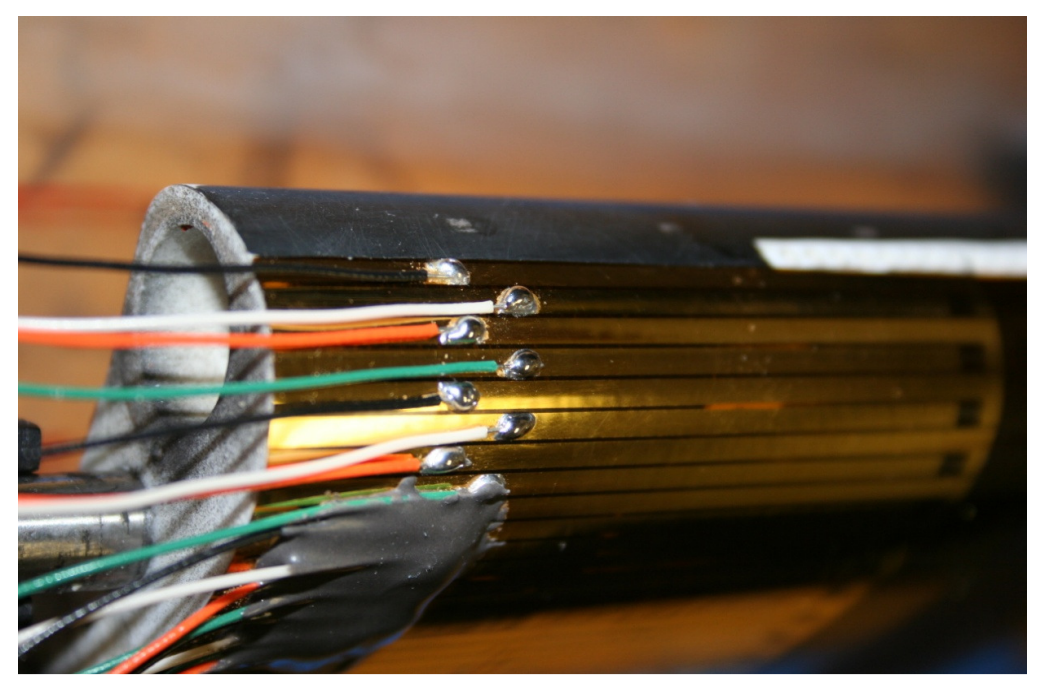

Figure B 2: Close up of SS TFGs showing soldered lead wires and epoxy covering

After the TFG lead wires were soldered, the resistance of each gage was measured and recorded. At this point, JB Weld epoxy was placed over the solder joints to protect the joints and to provide strain relief. TFG resistance was again checked and recorded after the application of epoxy. Once the TFG leads were fully soldered and covered in epoxy, the aluminum vane mounting block was attached to the vane and the lead wires were organized and numbered for ease of connection. TFG calibration could now be performed.

\section{TFG Calibration}

To calibrate the TFGs, the vane and mounting block assembly was placed into a thermocouple calibration oven. The temperature of the oven was raised in four discrete steps, at each step the gage resistance was measured along with the vane surface temperature and the oven air temperature. Upon reaching a peak calibration temperature of $\sim 75^{\circ} \mathrm{C}$, the temperature of the oven was lowered back to room temperature in four steps. Again, the gage resistance was measured along with air and vane surface temperature at each step. Resistance-temperature correlation was measured with increasing and decreasing temperature to ensure that the TFGs did not exhibit hysteresis effects. No significant hysteresis effects were seen in the data. Typically 12 hours was left between steps to ensure that the vane was at a steady-state condition.

After taking data for a range of oven temperatures, a line fit was performed to determine the resistance-temperature correlation equations for each of the 25 TFGs. All data points (both at increasing and decreasing temperatures) were used for the line fits, as none of the gages appeared to exhibit hysteresis. Calibrations were performed twice: once before tunnel entry and once again 
after exiting the tunnel. The results of both calibrations were then used to determine new resistance-temperature correlation equations for final data reduction.

\section{TFG Data Collection}

It is not practical to directly measure TFG resistance change, so a method is needed to convert resistance into a more measurable quantity such as voltage. A Wheatstone bridge is a device capable of performing this task. In this case, the TFG acts as one arm of a Wheatstone bridge, and the data reduction system measures the change in voltage across the bridge itself. The gage is also run in series with a potentiometer, allowing the bridge to be zeroed to adjust for dayto-day fluctuations in TFG resistance. A schematic demonstrating this concept can be seen in figure B-3.

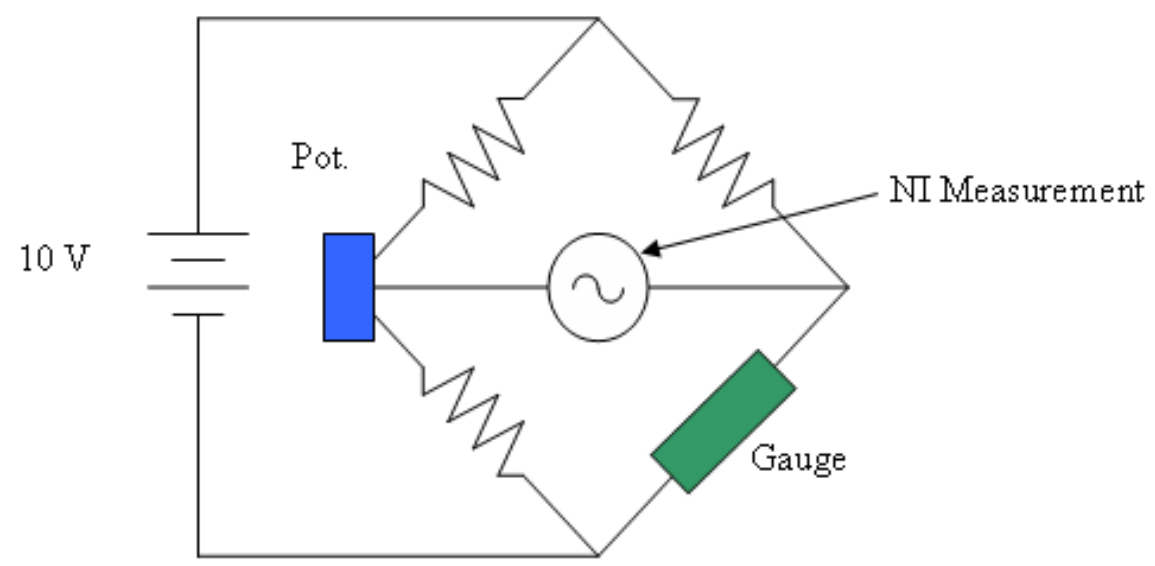

Figure B 3: Wheatstone bridge schematic from Nasir [B-1]

Prior to the first run of the day, the TFG resistance for each gage is recorded and each Wheatstone bridge is zeroed. Data is recorded by a National Instruments SCXI - 1600 data acquisition system. Based on the magnitude of the voltage recorded, the SCXI -1600 amplifier gain was set to 500 and the on-board signal filter was set to $10 \mathrm{kHz}$. TFG voltage data was recorded at a frequency of $1000 \mathrm{~Hz}$ for a duration of 30sec. Surface thermocouple data and film cooling circuit pressures were also recorded at the same frequency and duration. 


\section{References}

[B-1] Nasir,S., Bolchoz, T., Ng, W.F., Zhang, L.J., Moon, H.K., Anthony, R.J., 2008, “Showerhead Film Cooling Performance of a Turbine Vane in a Transonic Cascade," ASME IMECE 2008, Paper 66528. 


\section{Appendix C: Measurement Uncertainty}

There are two parts to experimental uncertainty: bias error and precision error. Precision error could be defined by the error seen in run-to-run repeatability, while bias error results from equipment used for the tests and testing methods. Bias error is what propagates through data reduction: these are the errors that must be fully quantified and tracked so as to determine the experimental uncertainty.

There are a number of main sources of bias error in surface heat transfer experiments: surface temperature error resulting from TFG calibration error, surface temperature error resulting from data acquisition error, recovery temperature error resulting from surface Mach number and data acquisition error, and coolant temperature error due to data acquisition error. Because a finite difference code is used to calculate $q$ ", tracking these errors through the code by numerical calculation would be extremely difficult. For this reason, the small perturbation method developed by Moffat [C-1] is used to determine the propagation of bias errors through the calculation of $q$ ”.

To apply this method, the upper and lower limits of bias (measurement) errors for the inputs to the finite difference code must first be found. In this case, as all of the inputs to the program are measurement devices, the average error for each instrument can be looked up in the manufacturer's literature. Once these errors are found, the program is run once using input data that corresponds to the upper limit of error and once with input data corresponding to the lower limit of error. By comparing the $q$ ” output from these runs to the non-error limit $q$ " data, the upper and lower error limits for $q$ " can be derived.

Once the error in heat flux is determined, error in heat transfer coefficient and film cooling effectiveness can also be determined. This step uses a numerical calculation technique as described in Brown and Coleman [C-2] tailored for the linear regression process. Both the bias error in each quantity on the $\mathrm{x}$ and $\mathrm{y}$-axis of the regression, and the precision error are accounted for in this process. Tabulated results by gage number for both the single and double run regressions follow. 
Table C 1: Uncertainties for single and double run regression technique

\begin{tabular}{|c|c|c|c|c|}
\hline \multirow[b]{2}{*}{ Gage \# } & \multicolumn{2}{|c|}{ Single Run Regression } & \multicolumn{2}{|c|}{ Double Run Regression } \\
\hline & $\begin{array}{c}\text { Uncertainty of HTC } \\
\text { (absolute value) } \mathrm{W} / \mathrm{m}^{\wedge} 2-\mathrm{K}\end{array}$ & $\begin{array}{l}\text { Uncertainty of Eta } \\
\text { (absolute value) }\end{array}$ & $\begin{array}{c}\text { Uncertainty of HTC } \\
\text { (absolute value) } \mathrm{W} / \mathrm{m}^{\wedge} 2-\mathrm{K}\end{array}$ & $\begin{array}{c}\text { Uncertainty of Eta } \\
\text { (absolute value) }\end{array}$ \\
\hline 1 & 69.68874375 & 0.118197688 & 29.77027154 & 0.057965457 \\
\hline 2 & 77.82175017 & 0.120419831 & 28.87939067 & 0.05679899 \\
\hline 3 & 78.50425719 & 0.120648724 & 28.81772263 & 0.056102615 \\
\hline 4 & 81.60731326 & 0.120857057 & 27.61920325 & 0.054923773 \\
\hline 5 & 81.73722842 & 0.120232165 & 26.42476079 & 0.053895606 \\
\hline 6 & 83.48389397 & 0.119432636 & 24.08487919 & 0.052633306 \\
\hline 7 & 77.04894927 & 0.114717069 & 18.50644697 & 0.051211911 \\
\hline 8 & 50.23858487 & 0.101741189 & 9.943002539 & 0.048764319 \\
\hline 9 & 20.28362589 & 0.083424815 & 7.190776965 & 0.045735803 \\
\hline 10 & 18.72188211 & 0.079980302 & 8.489334949 & 0.044305766 \\
\hline 11 & 17.56894269 & 0.077609017 & 9.387965734 & 0.043165403 \\
\hline 12 & 20.57227775 & 0.079521495 & 11.12991191 & 0.042114457 \\
\hline 13 & 25.02334451 & 0.08223573 & 13.48747897 & 0.040611571 \\
\hline 14 & 33.50496402 & 0.08743535 & 16.97768304 & 0.03735409 \\
\hline 15 & 48.40225264 & 0.094601652 & 20.78446825 & 0.029769754 \\
\hline 16 & 44.29361453 & 0.090660454 & 16.98697774 & 0.030802539 \\
\hline 17 & 29.86850721 & 0.082496459 & 13.18815675 & 0.036961481 \\
\hline 18 & 25.61135227 & 0.07933745 & 12.15180857 & 0.039143054 \\
\hline 19 & 23.16125105 & 0.077000349 & 10.68264046 & 0.041559748 \\
\hline 20 & 24.73278261 & 0.078738935 & 12.21887084 & 0.040520187 \\
\hline 21 & 23.90585709 & 0.078243198 & 11.67583992 & 0.042619818 \\
\hline 22 & 24.70874649 & 0.078830479 & 11.6626377 & 0.043302297 \\
\hline 23 & 24.88302193 & 0.07936602 & 11.92002025 & 0.043994681 \\
\hline 24 & 15.35159842 & 0.068679276 & 5.833511733 & 0.068931919 \\
\hline 25 & 22.77844255 & 0.078967617 & 12.65006697 & 0.045535018 \\
\hline
\end{tabular}

\section{References}

[C-1] Moffat, R. J., 1988, "Describing Uncertainties in Experimental Results," Exp. Thermal and Fluid Science, 1, pp. 3-17.

[C-2] Brown, K.H., Coleman, H.W., and Steele, W.G., 1995, "Estimating Uncertainty Intervals for Linear Regression,” AIAA-1995-0796. 


\section{Appendix D: Film Cooling Data Reduction}

\section{Chilled Coolant and Dual Regression Overview}

The procedure for chilled coolant runs is very similar to the room temperature process covered by Nasir [D-1]. However, there are some differences in the setup of the film cooling circuit. First, the heat exchanger was moved to a position not more than three feet from the entrance to the vane plenum. This reduces piping length between the heat exchanger and test section, reducing heat transfer from the atmosphere to the coolant. Second, solenoid valves were installed in the coolant circuit to allow the coolant flow to be turned on or off remotely from outside the tunnel.

Directly before a run, about 1 to 1.5 inches of liquid nitrogen was added to the heat exchanger. After closing/opening the required valves, the tunnel was started. At this point, the solenoid valves were actuated and coolant could start flowing through the coolant circuit. The coolant was timed to start flowing either directly at or slightly after tunnel start. This is so as to not create an uneven temperature distribution on the measurement vane surface. Unfortunately, this technique results in a large coolant dip at the moment the solenoid valves are actuated. The dip is a result of the coolant system purging at the beginning of the run. To avoid reducing data using an extremely transient coolant temperature, data reduction times were shifted to slightly later in the run where coolant temperature was near steady state. Figure D-1 shows a sample tunnel temperature-time history for a chilled coolant run, and figure D-2 is a sample plot of heat flux for a chilled coolant run.

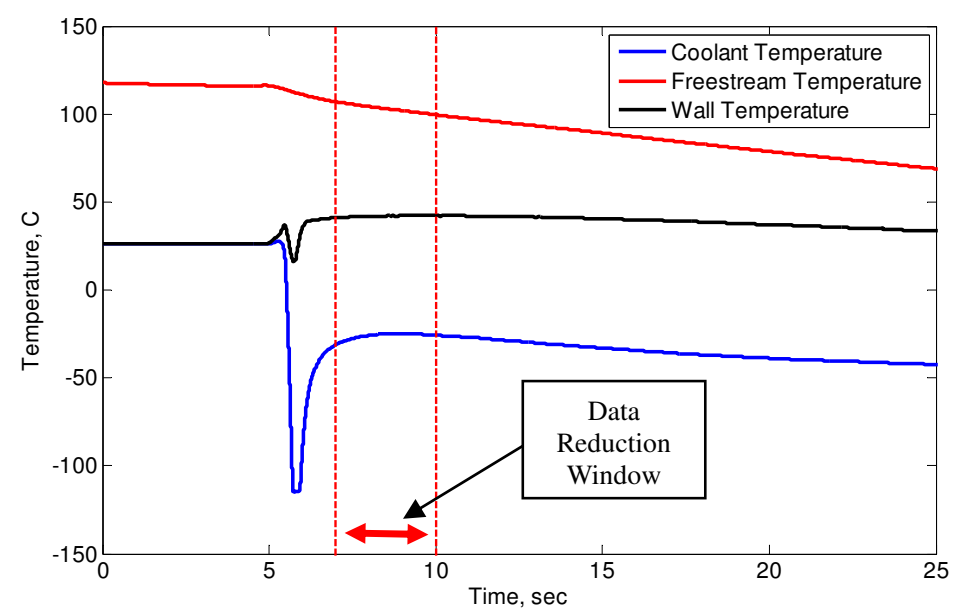

Figure D 1: Tunnel temperature response vs. time 


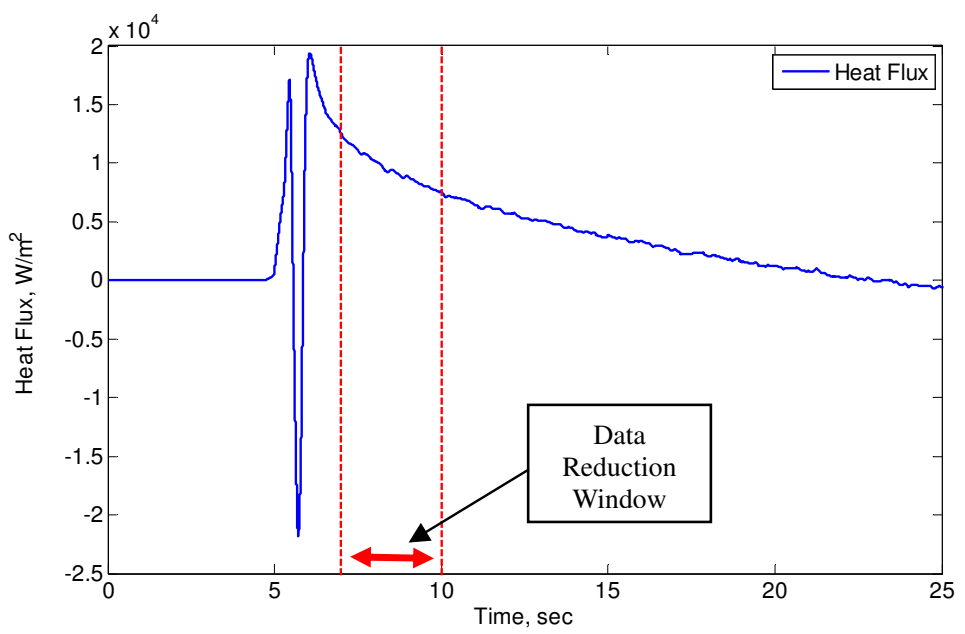

Figure D 2: Vane heat flux response vs. Time

The double run regression technique uses the same data reduction methods as single regression data. Wall heat flux is calculated separately for each run using the original single run programs as described in the main body of this paper. Heat flux and axis data for the linear regression is then fed into a separate program which performs the double run regression on both the chilled and room-temperature coolant data. This program only performs the linear regression, and uses $q$ " and other data calculated and stored by the single run programs.

In the course of exploring the possibilities of the double run regression technique, it was found that existing single run data could be corrected based on results obtained from the double run regression technique. This correction method assumes that the double run regression method yields more correct results due to considerably decreased uncertainty. This technique works by re-ordering equation D-1 and solving for recovery temperature. By solving for recovery temperature using heat transfer and film cooling effectiveness data from a double regression run, and wall temperature, heat flux, and coolant temperature data from a single regression run a corrected recovery temperature can be determined. This corrected recovery temperature is then compared with the recovery temperature calculated for the single regression run based on surface Mach number and assumed recovery factor using equation D-2, and a percent difference between the two is calculated. The percent difference can then be used as a correction factor to account for the extra uncertainty present in single regression runs in other data sets.

$$
\frac{q^{\prime \prime}}{T_{r}-T_{c}}=h\left(\frac{T_{r}-T_{w}}{T_{r}-T_{c}}\right)-h \eta
$$

\section{Recovery Temperature}

Recovery temperature for the double run regression method is calculated using equation D-2 below.

$$
T_{r}=T_{0, \infty}\left(\frac{1+r \frac{\gamma-1}{2} M^{2}}{1+\frac{\gamma-1}{2} M^{2}}\right)
$$


Based on this equation, recovery temperature is computed using vane surface Mach number and recovery factor, $r$. For the purposes of this study, recovery factor is assumed to be that of a turbulent flat plate boundary layer, where $r$ $=\mathrm{Pr}^{1 / 3}$. In the past, it was attempted to measure recovery temperature based on a data reduction process used for BR $=0$ cases. This reduction process is also covered in detail in Nasir [D-1]. However, for the present study, it was decided to use an assumed recovery factor due to the addition of extra film cooling rows on the pressure and suction sides of the measurement vane. Additional film cooling holes present a problem for measuring uncooled heat transfer distributions by way of $\mathrm{BR}=0$ cases. Due to varying surface pressures at different film cooling hole locations, there could be recirculation inside the film cooling plenum from one row of holes to another. This could result in an artificial film cooling effect when it is not expected. The possibility of coolant recirculation made it implausible to measure recovery temperature, so the turbulent flat plate recovery factor was assumed.

\section{References}

[D-1] Nasir, S., 2008, "Showerhead Film Cooling Performance of a Turbine Vane at High Freestream Turbulence in a Transonic Cascade,” Dissertation, Virginia Polytechnic Institute and State University 
Appendix E: Tabulated Heat Transfer, Adiabatic Effectiveness, and NHFR Comparison Data

Table E 1: Heat Transfer and Film Effectiveness Data, Mex $=0.60$

\begin{tabular}{|c|c|c|c|c|c|c|}
\hline \multicolumn{7}{|c|}{ Mex $=0.60$} \\
\hline & \multicolumn{3}{|c|}{$\mathrm{BR}=2.0$} & \multicolumn{3}{|c|}{$B R=1.5$} \\
\hline$x / C$ & HTC & Eta & Nu & HTC & Eta & $\mathrm{Nu}$ \\
\hline-0.173 & 367.0275 & 0.542117 & 955.3202 & 296.5973 & 0.545274 & 772.0003 \\
\hline-0.208 & 279.0731 & 0.440745 & 726.3875 & 233.5784 & 0.423738 & 607.9712 \\
\hline 0.26 & 255.4495 & 0.382991 & 664.8985 & 202.5586 & 0.316912 & 527.231 \\
\hline-0.312 & 236.2781 & 0.329878 & \begin{tabular}{|l|}
614.9982 \\
\end{tabular} & 202.0522 & 0.274041 & 525.913 \\
\hline 0.364 & 242.0708 & 0.316203 & 630.0758 & 195.4389 & 0.234088 & 508.6994 \\
\hline-0.416 & 242.3174 & 0.279304 & 630.7175 & 204.0164 & 0.200817 & 531.0255 \\
\hline-0.468 & 253.9033 & 0.285931 & 660.874 & 211.9839 & 0.202304 & 551.7638 \\
\hline 0.52 & 249.3828 & 0.253644 & 649.1078 & 218.8518 & 0.19098 & 569.64 \\
\hline 0.916 & 427.4618 & 0.101824 & 1112.622 & 395.0432 & 0.040905 & 1028.241 \\
\hline 0.864 & 425.9586 & 0.11133 & 1108.71 & 395.248 & 0.053772 & 1028.774 \\
\hline 0.812 & 432.1505 & 0.121643 & 1124.826 & 403.4648 & 0.068336 & 1050.161 \\
\hline 0.76 & 421.564 & 0.128857 & \begin{tabular}{|l|}
1097.271 \\
\end{tabular} & 397.9749 & 0.083734 & 1035.872 \\
\hline 0.708 & 413.4554 & 0.130698 & 1076.165 & 391.3105 & 0.089125 & 1018.525 \\
\hline 0.656 & 390.6976 & 0.132744 & 1016.93 & 358.7055 & 0.083191 & 933.6591 \\
\hline 0.448 & 173.9084 & 0.221121 & 452.6586 & 146.2103 & 0.133275 & 380.5645 \\
\hline 0.396 & 192.258 & 0.275208 & 500.4202 & 187.7459 & 0.268435 & 488.6758 \\
\hline 0.344 & 246.0283 & 0.348553 & 640.3765 & 253.1921 & 0.367025 & 659.0229 \\
\hline 0.292 & 311.1744 & 0.392654 & 809.9426 & 326.8159 & 0.417613 & 850.6552 \\
\hline 0.24 & 418.8656 & 0.448791 & 1090.247 & 441.682 & 0.474254 & 1149.635 \\
\hline 0.188 & 619.5605 & 0.537251 & 1612.627 & 647.7979 & 0.564125 & 1686.125 \\
\hline
\end{tabular}


Table E 2: Film cooling effectiveness and heat transfer data, $M e x=0.85$

\begin{tabular}{|c|c|c|c|c|c|c|c|c|c|}
\hline \multicolumn{10}{|c|}{$M a=0.85$} \\
\hline & \multicolumn{3}{|c|}{$B R=2.0$} & \multicolumn{3}{|c|}{$B R=1.5$} & \multicolumn{3}{|c|}{$B R=1.0$} \\
\hline$x / C$ & HTC & Eta & $\mathrm{Nu}$ & HTC & Eta & $\mathrm{Nu}$ & HTC & Eta & $\mathrm{Nu}$ \\
\hline-0.173 & 578.3215 & 0.570256 & 1505.288 & 429.777 & 0.554663 & 1118.648 & 318.7725 & 0.521482 & 829.7194 \\
\hline-0.208 & 411.2221 & 0.490084 & 1070.352 & 327.0875 & 0.458018 & 851.3621 & 224.5443 & 0.330783 & 584.4566 \\
\hline-0.26 & 357.5234 & 0.43384 & \begin{tabular}{|l|}
930.5822 \\
\end{tabular} & 302.5519 & 0.398523 & 787.4993 & 209.1579 & 0.233765 & 544.4082 \\
\hline-0.312 & 326.9695 & 0.389051 & 851.0549 & 280.2039 & 0.332717 & 729.3308 & 208.5626 & 0.177777 & 542.8587 \\
\hline-0.364 & 340.514 & 0.379397 & 886.3094 & 287.7486 & 0.326859 & 748.9686 & 214.1748 & 0.174243 & 557.4664 \\
\hline-0.416 & 325.1177 & 0.328375 & 846.2349 & 284.9494 & 0.271418 & 741.6825 & 223.0665 & 0.131966 & 580.6102 \\
\hline-0.468 & 333.4004 & 0.326093 & 867.7936 & \begin{tabular}{|l|}
294.7398 \\
\end{tabular} & 0.268356 & 767.1657 & 230.5392 & 0.128748 & 600.0605 \\
\hline-0.52 & 330.8863 & 0.302168 & 861.2498 & 297.2108 & 0.246881 & 773.5974 & 231.1506 & 0.09977 & 601 \\
\hline 0.916 & 530.5878 & 0.138131 & 1381.044 & 517.8665 & 0.107752 & 1347.932 & 533.7085 & 0.111531 & 1389.167 \\
\hline 0.864 & 529.7613 & 0.146953 & 1378.893 & 508.107 & 0.110737 & 1322.53 & 525.4729 & 0.115746 & 1367.731 \\
\hline 0.812 & 536.2586 & 0.156407 & 1395.805 & 516.4046 & 0.123525 & 1344.127 & 536.4682 & 0.130581 & 1396.35 \\
\hline 0.76 & 528.0635 & \begin{tabular}{|l|}
0.171718 \\
\end{tabular} & \begin{tabular}{|l|}
1374.474 \\
\end{tabular} & \begin{tabular}{|l|}
508.7514 \\
\end{tabular} & 0.141141 & 1324.207 & 524.8669 & 0.145912 & 1366.154 \\
\hline 0.708 & 517.4173 & 0.176489 & 1346.763 & 497.339 & 0.148557 & 1294.502 & 513.0922 & 0.155038 & 1335.506 \\
\hline 0.656 & 487.9753 & 0.185382 & 1270.13 & 462.8558 & 0.158212 & 1204.748 & 460.597 & 0.153629 & 1198.868 \\
\hline 0.448 & 208.0163 & 0.307686 & 541.4367 & 212.3295 & 0.333827 & 552.6634 & 192.0503 & 0.29081 & 499.8795 \\
\hline 0.396 & 237.3749 & 0.36097 & 617.8531 & \begin{tabular}{|l|}
247.0478 \\
\end{tabular} & 0.388551 & 643.0302 & 239.5106 & 0.3788 & 623.412 \\
\hline 0.344 & 290.4573 & 0.396801 & 756.019 & 296.9864 & 0.412989 & 773.0133 & 291.5734 & 0.408915 & 758.9238 \\
\hline 0.292 & 367.2979 & 0.418355 & 956.0239 & 358.9862 & 0.415502 & 934.3897 & 365.4602 & 0.425206 & 951.2407 \\
\hline 0.24 & 507.974 & 0.459595 & 1322.184 & 482.4878 & 0.444308 & 1255.847 & 493.5815 & 0.457988 & 1284.722 \\
\hline 0.188 & 793.925 & 0.54125 & 2066.473 & 720.6607 & 0.517763 & 1875.777 & 737.0034 & 0.536673 & 1918.315 \\
\hline
\end{tabular}


Table E 3: Film cooling effectiveness and heat transfer data, $M e x=1.0$

\begin{tabular}{|c|c|c|c|c|c|c|c|c|c|}
\hline \multicolumn{10}{|c|}{ Mex $=1.00$} \\
\hline & \multicolumn{3}{|c|}{$B R=2.0$} & \multicolumn{3}{|c|}{$B R=1.5$} & \multicolumn{3}{|c|}{$B R=1.0$} \\
\hline$x / C$ & HTC & Eta & $\mathrm{Nu}$ & HTC & Eta & $\mathrm{Nu}$ & HTC & Eta & $\mathrm{Nu}$ \\
\hline-0.173 & 482.1389 & 0.545768 & 1254.939 & 437.9805 & 0.551565 & 1140.001 & 349.3667 & 0.544966 & 909.3515 \\
\hline-0.208 & 426.6263 & 0.491169 & \begin{tabular}{|l|}
1110.447 \\
\end{tabular} & 367.0314 & \begin{tabular}{|l|l|}
0.475482 \\
\end{tabular} & 955.3303 & 344.4025 & 0.472752 & 896.4304 \\
\hline-0.26 & 441.8833 & 0.448892 & \begin{tabular}{|l}
1150.159 \\
\end{tabular} & \begin{tabular}{|l|}
347.9344 \\
\end{tabular} & \begin{tabular}{|l|}
0.421887 \\
\end{tabular} & 905.6235 & 342.3384 & 0.416951 & 891.0579 \\
\hline-0.312 & 355.9623 & 0.343451 & 926.519 & 368.0921 & 0.39943 & 958.0912 & 335.3093 & 0.357643 & 872.7622 \\
\hline-0.364 & 432.0213 & 0.385573 & 1124.49 & 367.6178 & 3877 & 956.8565 & 334.7164 & 0.346312 & 871.219 \\
\hline-0.416 & 395.9472 & 0.336171 & 1030.594 & 372.1958 & 0.341537 & 968.7725 & 347.9397 & 0.307978 & 905.6373 \\
\hline-0.468 & 413.4403 & 0.340981 & 1076.126 & 378.6586 & 0.328342 & 985.5943 & 367.5128 & 0.310209 & 956.5832 \\
\hline-0.52 & 40 & 0. & 104 & 3 & 29 & 74 & & 335 & 279 \\
\hline 0.916 & 554.9157 & 0.128421 & 1444.366 & 591.2255 & 0.112729 & 1538.875 & 660.8271 & 0.151484 & 1720.039 \\
\hline 0.864 & 564.8274 & 0.140768 & 1470.165 & 607.1809 & 0.139017 & \begin{tabular}{|l}
1580.405 \\
\end{tabular} & 569.5593 & 0.105751 & 1482.481 \\
\hline 0.812 & 572.8501 & \begin{tabular}{|l|l|}
0.154573 \\
\end{tabular} & \begin{tabular}{|l|}
1491.047 \\
\end{tabular} & 566.2498 & 0.129811 & 1473.867 & 511.1154 & 0.076807 & 1330.36 \\
\hline 0.76 & 528.1046 & 0.15066 & \begin{tabular}{|l|}
1374.581 \\
\end{tabular} & 547.9083 & 0.144397 & 1426.127 & 550.3455 & 0.140078 & 1432.471 \\
\hline 0.708 & 519.4225 & 0.154416 & \begin{tabular}{|l}
1351.983 \\
\end{tabular} & \begin{tabular}{|l|}
553.5072 \\
\end{tabular} & \begin{tabular}{|l|}
0.152017 \\
\end{tabular} & 1440.7 & 583.4024 & 0.169883 & 1518.513 \\
\hline 0.656 & 522.3173 & 0.165978 & 1359.517 & 555.3893 & 0.161352 & 1445.599 & 595.3149 & 0.18805 & 1549.52 \\
\hline 0.448 & 252.4175 & 0.327891 & 657.0067 & \begin{tabular}{|l}
267.6672 \\
\end{tabular} & \begin{tabular}{|l}
0.348769 \\
\end{tabular} & \begin{tabular}{|l}
696.6995 \\
\end{tabular} & 314.107 & 0.428212 & 817.5755 \\
\hline 0.396 & 272.6737 & 0.354011 & 709.7307 & 291.5811 & 0.37185 & 758.944 & 326.5377 & 0.424702 & 849.9309 \\
\hline 0.344 & 337.2356 & 0.39541 & 877.776 & 352.9689 & 0.401291 & 918.7275 & 386.3011 & 0.43658 & 1005.487 \\
\hline 0.292 & 433.9291 & 0.424769 & 1129.455 & 448.0474 & 0.424592 & 1166.203 & 494.2894 & 0.460087 & 1286.565 \\
\hline 0.24 & 591.1359 & 0.46374 & 1538.642 & 609.9963 & 0.462295 & 1587.733 & 664.5791 & 0.491345 & 1729.804 \\
\hline 0.188 & 858.4712 & 0.534714 & 2234.478 & \begin{tabular}{|l|}
879.8427 \\
\end{tabular} & \begin{tabular}{|l|}
0.531548 \\
\end{tabular} & \begin{tabular}{|l|}
2290.105 \\
\end{tabular} & 931.3077 & 0.55583 & 2424.061 \\
\hline
\end{tabular}


Table E 4: Normalized heat transfer coefficient and NHFR, Mex $=0.85, B R=2.0$

\begin{tabular}{|c|c|c|}
\hline \multicolumn{3}{|c|}{$M a=0.85$} \\
\hline & \multicolumn{2}{|c|}{ BR $=2.0$} \\
\hline$x / C$ & $H / H O$ & NHFR \\
\hline-0.173 & 2.213727 & 0.890258 \\
\hline-0.208 & 1.735113 & 0.68214 \\
\hline-0.26 & 1.546145 & 0.57182 \\
\hline-0.312 & 1.427845 & 0.497997 \\
\hline-0.364 & 1.442881 & 0.469495 \\
\hline-0.416 & 1.350352 & 0.388685 \\
\hline-0.468 & 1.297746 & 0.407564 \\
\hline-0.52 & 1.253681 & 0.37769 \\
\hline & & \\
\hline 0.916 & 0.973245 & 0.250813 \\
\hline 0.864 & 0.908644 & 0.313902 \\
\hline 0.812 & 0.924216 & 0.316707 \\
\hline 0.76 & 0.900086 & 0.357516 \\
\hline 0.708 & 0.908368 & 0.358827 \\
\hline 0.656 & 0.905586 & 0.374213 \\
\hline 0.448 & 1.584686 & 0.227957 \\
\hline 0.396 & 1.729566 & 0.310971 \\
\hline 0.344 & 1.803167 & 0.389331 \\
\hline 0.292 & 1.903329 & 0.423782 \\
\hline 0.24 & 2.09469 & 0.509824 \\
\hline 0.188 & 2.995564 & 0.706686 \\
\hline & & \\
\hline
\end{tabular}

